\title{
The System for Integrating Multiplatform Data to Build the Atmospheric Column (SIMBA) Precipitation Observation Fusion Framework ${ }^{\mathscr{D}}$
}

\author{
STEPHANIE M. WINGO \\ NASA Marshall Space Flight Center, and Universities Space Research Association, Huntsville, Alabama \\ Walter A. Petersen And PAtrick N. Gatlin \\ NASA Marshall Space Flight Center, Huntsville, Alabama \\ ChARANJit S. PABLA AND DAVID A. MARKS \\ Science Systems and Applications, Inc., and NASA Wallops Flight Facility, Wallops Island, Virginia \\ DAVID B. WOLFF \\ NASA Wallops Flight Facility, Wallops Island, Virginia
}

(Manuscript received 31 October 2017, in final form 6 April 2018)

\begin{abstract}
Researchers now have the benefit of an unprecedented suite of space- and ground-based sensors that provide multidimensional and multiparameter precipitation information. Motivated by NASA's Global Precipitation Measurement (GPM) mission and ground validation objectives, the System for Integrating Multiplatform Data to Build the Atmospheric Column (SIMBA) has been developed as a unique multisensor precipitation data fusion tool to unify field observations recorded in a variety of formats and coordinate systems into a common reference frame. Through platform-specific modules, SIMBA processes data from native coordinates and resolutions only to the extent required to set them into a user-defined three-dimensional grid. At present, the system supports several ground-based scanning research radars, NWS NEXRAD radars, profiling Micro Rain Radars (MRRs), multiple disdrometers and rain gauges, soundings, the GPM Microwave Imager and DualFrequency Precipitation Radar on board the Core Observatory satellite, and Multi-Radar Multi-Sensor system quantitative precipitation estimates. SIMBA generates a new atmospheric column data product that contains a concomitant set of all available data from the supported platforms within the user-specified grid defining the column area in the versatile netCDF format. Key parameters for each data source are preserved as attributes. SIMBA provides a streamlined framework for initial research tasks, facilitating more efficient precipitation science. We demonstrate the utility of SIMBA for investigations, such as assessing spatial precipitation variability at subpixel scales and appraising satellite sensor algorithm representation of vertical precipitation structure for GPM Core Observatory overpass cases collected in the NASA Wallops Precipitation Science Research Facility and the GPM Olympic Mountain Experiment (OLYMPEX) ground validation field campaign in Washington State.
\end{abstract}

\section{Introduction}

NASA's Global Precipitation Measurement (GPM) mission aims to advance understanding of Earth's water

Supplemental information related to this paper is available at the Journals Online website: https://doi.org/10.1175/JTECH-D-17-0187.s1.

Corresponding author: Dr. Stephanie M. Wingo, stephanie.m.wingo@ nasa.gov and energy cycles and has a broader goal of improving prediction capability for high-impact weather and climate events in order to benefit society (Hou et al. 2014; Skofronick-Jackson et al. 2017). Recent decades have seen tremendous precipitation science advancement, and there is now an unprecedented suite of space- and ground-based precipitation sensors in use around the world. Despite these advances, there remain impediments to a complete understanding of precipitation processes in a variety of climatic, topographic, and system 
regimes (e.g., Medina et al. 2005; Hirpa et al. 2010; Kulie et al. 2010; Medina and Houze 2015; Tan et al. 2016). In addition to addressing outstanding science questions, GPM includes a ground validation (GV) component focused on direct statistical and physical validation of satellite precipitation observations. These objectives, especially those associated with GPM physical validation, motivated a series of GPM GV field campaigns collecting targeted observations of precipitation with a vast array of instruments in a variety of regimes (e.g., Jensen et al. 2016; SkofronickJackson et al. 2015; Chen and Chandrasekar 2015; Petersen et al. 2016; Houze et al. 2017).

Answering GPM's validation and science challenges requires multisensor datasets that leverage benefits and mitigate concerns inherent to specific observing platforms. These data must be combined to "build" a view of the atmospheric column in order to characterize precipitation structure and variability and to elucidate details about the processes governing the type and amount of precipitation reaching the ground in a range of environments. Multisensor datasets have been identified as key for satellite validation (e.g., Chandrasekar et al. 2008). The GPM GV Validation Network (VN) routinely generates beammatched products for space- and ground-based radar comparisons (Schwaller and Morris 2011). The MultiRadar Multi-Sensor system (MRMS; Zhang et al. 2016) produces gridded quantitative precipitation estimation (QPE) products for the conterminous United States (CONUS) and southern Canada based on inputs from satellite, ground-based radars, rain gauge networks, and model analyses. As such, MRMS products have been used for validating satellite-based precipitation estimates (e.g., Kirstetter et al. 2012; Tan et al. 2016). Several recent studies have used various combinations of ground-based radars, space-based sensors, and surface-based disdrometers to study precipitation and processes (e.g., Gourley et al. 2010; Kim et al. 2014; Bringi et al. 2015; Thurai et al. 2017). While all of these works employ multisensor datasets, the means by which they do so varies.

Working with diverse datasets often requires tedious initial effort, as observations are recorded in multiple formats and coordinate systems, and at varying resolutions. It has become commonplace in the precipitation, radar, and satellite communities for individual researchers or teams to develop disparate practices and/or codes to perform nearly identical initial steps for research tasks, such as interpolating or resampling values to a Cartesian grid (e.g., Testud and Chong 1983; Mohr et al. 1986; Oye et al. 1995; Collis et al. 2010). The System for Integrating Multiplatform Data to Build the Atmospheric Column (SIMBA) provides researchers a streamlined tool to fuse multiplatform precipitation observations to a user-defined common 3D Cartesian grid, which readily facilitates scientific analyses. SIMBA approaches this task with a collection of platform-specific modules and writes concomitant data from all supported sensors (Table 1) to a single file. This SIMBA atmospheric column data product contains all of the available data fields set into the userdefined 3D grid as well as key parameters for each platform preserved from the native files.

This paper documents the initial development of the SIMBA data fusion framework as a tool aimed at making more efficient precipitation research possible. Section 2 provides an overview of SIMBA, including supported platforms, system dependencies, and the output atmospheric column data file format. Subsequent sections present examples of initial SIMBA application to GPM Core Observatory satellite overpass cases at two locations: a multisensor radar, disdrometer, and gauge network within NASA Wallops Flight Facility's Precipitation Science Research Facility (WPRF; Wolff et al. 2015); and the GPM Olympic Mountain Experiment (OLYMPEX) GV field campaign (Petersen et al. 2016; Houze et al. 2017). The final section provides a summary and briefly notes ongoing SIMBA improvements.

\section{System overview}

The SIMBA framework is a packaged library of Interactive Data Language (IDL; http://www.harrisgeospatial.com) code consisting of platform-specific modules, functions, and procedures that work together to generate the atmospheric column data product. SIMBA unifies what are often cumbersome first steps in precipitation research: gathering data from diverse instrumentation and handling multiple data formats and coordinate systems to synthesize observations into a common 3D context. By streamlining these steps into a single tool, SIMBA provides an efficient starting point for an array of projects, including precipitation process studies, evaluations of variabilities within a spaceborne sensor's field of view, and assessments of retrieval algorithm assumptions. Figure 1 shows a schematic overview of the system, and Table 1 provides an overview of the instrument platforms and data products currently supported in SIMBA. These sensors include ground-based scanning and profiling radars; surface-based disdrometers and rain gauges, thermodynamic soundings; the GPM Microwave Imager (GMI) and Dual-Frequency Precipitation Radar (DPR) on board the Core Observatory satellite; and QPE from MRMS, which provides multisensor NEXRAD-centric estimates of precipitation across CONUS (Zhang et al. 2016).

A key feature of the system is its flexibility: SIMBA can be applied to any location, allowing the user to define the column grid center point, total vertical and 
TABLE 1. Overview of sensors and data fields included in the SIMBA data fusion framework. Fields available in these PPS products are described by the algorithm theoretical basis documents (ATBDs) for each product (e.g., GSFC 2017a,b; Iguchi et al. 2017); also see main text.

\begin{tabular}{lcc}
\hline \hline \multicolumn{1}{c}{ Sensor } & \multicolumn{1}{c}{ Type/description } & Data products/fields supported in SIMBA \\
\hline GMI & Conically scanning passive microwave radiometer & L1C and 2AGPROF GMI PPS product fields \\
DPR & (13 channels, 10-183 GHz) & \\
& Electronically scanning radar (Ka band, & 2ADPR PPS product fields \\
NPOL & $13.6 \mathrm{GHz} ;$ Ku band, 35.5 GHz) & \\
& Research S-band polarimetric Doppler radar & $Z, Z_{\mathrm{cor}}, V_{r}, \mathrm{SW}, Z_{\mathrm{dr}}, \phi_{\mathrm{dp}}, \rho_{\mathrm{hv}}, K_{\mathrm{dp}}, D_{0}, D_{M}, N_{W}$, \\
NEXRAD & (stationary and field deployable) & RR, HID \\
& Operational S-band polarimetric Doppler radar & $Z, Z_{\mathrm{cor}}, V_{r}, \mathrm{SW}, Z_{\mathrm{dr}}, \phi_{\mathrm{dp}}, \rho_{\mathrm{hv}}, K_{\mathrm{dp}}, D_{0}, D_{M}, N_{W}$, \\
D3R & network (stationary sites) & RR, HID \\
& Research Ka-/Ku-band polarimetric Doppler & Ka: $Z, V_{r}, \mathrm{SW}, Z_{\mathrm{dr}}, \phi_{\mathrm{dp}}, \rho_{\mathrm{hv}}$ \\
DOW & radar (field deployable) & Ku: $Z, Z_{\mathrm{cor}}, V_{r}, \mathrm{SW}, Z_{\mathrm{dr}}, \phi_{\mathrm{dp}}, \rho_{\mathrm{hv}}, K_{\mathrm{dp}}$ \\
& Research X-band polarimetric Doppler radar & $Z, Z_{\mathrm{cor}}, V_{r}, \mathrm{SW}, Z_{\mathrm{dr}}, \phi_{\mathrm{dp}}, \rho_{\mathrm{hv}}, K_{\mathrm{dp}}$ \\
MRR & (field deployable) & \\
2DVD & Vertically pointing K-band profiling radar & $Z, Z_{\mathrm{cor}}, W$, two-way PIA, LWC, RR, $D_{M}, N_{W}$ \\
Parsivel & Surface, dual-direction optical disdrometer & DSD, RR, LWC, Rayleigh scattering $Z$ \\
Pluvio & Surface, single-direction optical disdrometer & DSD, RR, LWC, Rayleigh scattering $Z$ \\
Tipping buckets & Surface, weighing rain gauge & Precipitation rate \\
MRMS (Zhang et al. 2016) & Surface, catchment rain gauge & Rain rate \\
& 0.01 $\times 0.01^{\circ}$ gridded QPE product derived from & Precipitation rate, precipitation type category, \\
Radiosondes & CONUS radars and rain gauge data & radar quality index \\
& Vaisala RS92 and Sippican Mark II sondes & Temperature, dewpoint, wind speed, and wind \\
& (OLYMPEX campaign) & direction profiles; CAPE; CIN; precipitable \\
& & water; LCL; LFC; and EL levels
\end{tabular}

horizontal extent, and spacing. Each platform-specific module sets the available data into the user-defined grid, and the system writes the new atmospheric column data file in netCDF format (Unidata 2016). Distinguishing properties of each native dataset (including exact platform locations, operation modes, and algorithm versions) are maintained as attributes. Table 2 lists the sensor/data parameters preserved for each supported platform. This affords the simplicity of a single-file starting point for a wide variety of investigations. Extensive resources for reading netCDF files are widely available within the most prevalent coding tools used in the precipitation research community, including IDL and Python. The following subsections detail SIMBA's components, dependencies, and the structure of SIMBA's output.

\section{a. Platform-specific modules}

To accommodate differing native input formats and to maintain data attributes for each platform, separate SIMBA modules handle data from each sensor in Table 1. Input to each module includes the data file and parameters of the user-defined SIMBA column grid. Modules process observations only to the extent required to set the data into the column grid and to return gridded, interpolated, and/ or a subset of values (depending on the instrument type/ original data resolution) to the main SIMBA procedure.
The modular philosophy of SIMBA is intended to support a convenient approach to continued and future development, even allowing users to create additional modules for new platforms. While the examples in sections 3 and 4 are within the United States, the system's architecture permits the use of currently supported sensors when deployed at non-U.S. locations [e.g., as part of the GPM Cold Season Precipitation Experiment (GCPEx) field campaign; Skofronick-Jackson et al. 2015] and the addition of ground-based platform modules, noted in more detail below.

Input for the NASA polarimetric radar (NPOL) and NWS NEXRAD/WSR-88D are in Universal Format (UF; Barnes 1980), having undergone GPM GV dualpolarimetric quality control processing (Marks et al. 2011; Pippitt et al. 2013; Pippitt et al. 2015) at Goddard Space Flight Center. This processing includes empirically based retrieval of the raindrop size distribution (DSD) mass-weighted mean diameter and the normalized intercept parameter (Pippitt et al. 2015; Petersen et al. 2017), computation of rain rates (RR) following three leading algorithms (Cifelli et al. 2002; Bringi et al. 2004; Chen et al. 2017), and hydrometeor classification (following Dolan et al. 2013). SIMBA allows input of data from multiple NEXRAD radars at the same time, and all NEXRAD in the GPM GV VN are supported. The NASA Dual-Frequency, Dual-Polarized Doppler 

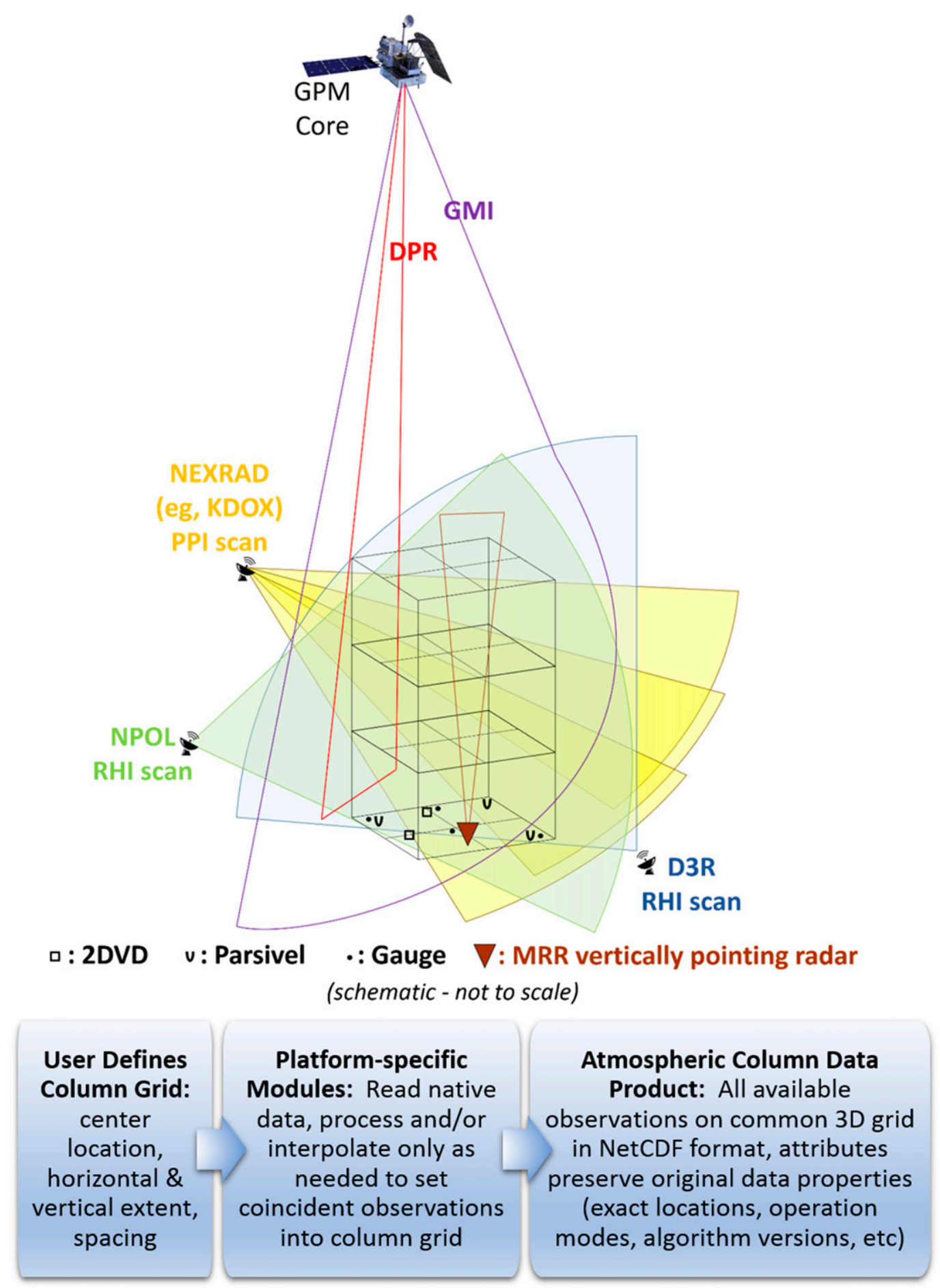

FIG. 1. Schematic example of a SIMBA column grid placed in an intensively sampled region and flowchart depicting the process of generating atmospheric column data files. The SIMBA framework enables more efficient precipitation science by fusing targeted GPM GV observations from several instruments to a common 3D grid.

Radar (D3R), designed specifically with the GPM DPR and GPM mission science in mind (Vega et al. 2014), currently operates routinely within the NASA WPRF and was successfully deployed in many of the GPM GV field campaigns (e.g., Chen and Chandrasekar 2015; Chandrasekar et al. 2016). Input D3R files are in netCDF format (single sweep per file) and have gone through a basic level of quality control at Colorado State 
TABLE 2. Preserved attributes, by data platform/type, included in the atmospheric column data file.

\begin{tabular}{|c|c|}
\hline Platforms and Attribute Names & Description \\
\hline \multicolumn{2}{|l|}{$\begin{array}{l}\text { Ground-based radars: NPOL, NEXRAD, D3R, } \\
\text { DOW, MRR }\end{array}$} \\
\hline latitude & Radar site latitude \\
\hline longitude & Radar site longitude \\
\hline elevation & Radar site elevation (MSL) \\
\hline operation_mode & Radar scan mode (PPI, RHI, MRR) \\
\hline wavelength & Radar wavelength (m) \\
\hline frequency & Radar frequency $(\mathrm{GHz})$ \\
\hline beam_width & Radar half-power beamwidth $\left(^{\circ}\right)$ \\
\hline gate_size & Radar gate size $(\mathrm{m})$ \\
\hline timestamp & Time stamp for start of the radar volume/input file \\
\hline offset_vs_main & Offset (s) of time stamp relative to the main platform time stamp \\
\hline \multicolumn{2}{|l|}{ Ground-based disdrometers: 2DVD, Parsivel } \\
\hline latitude & Disdrometer site latitude \\
\hline longitude & Disdrometer site longitude \\
\hline operation_mode & Disdrometer type \\
\hline timestamp & Time stamp of disdrometer observations \\
\hline offset_vs_main & Offset (s) of time stamp relative to the main platform time stamp \\
\hline \multicolumn{2}{|l|}{ Ground-based gauges: Pluvio, tipping buckets } \\
\hline latitude & Gauge site latitude \\
\hline longitude & Gauge site longitude \\
\hline operation_mode & Gauge type \\
\hline timestamp & Time stamp of gauge observations \\
\hline offset_vs_main & Offset (s) of time stamp relative to the main platform time stamp \\
\hline \multicolumn{2}{|l|}{ Satellite-based sensors: GMI, DPR } \\
\hline file_type & PPS product data type (e.g., 2A-CS, 1C) \\
\hline frequency & Channels/bands used (GHz) \\
\hline algorithm_name & PPS product algorithm (e.g., GPROF2017v1) \\
\hline orbit_number & PPS product orbit number (e.g., 010019) \\
\hline data_version & PPS product data version number (e.g., V05A) \\
\hline timestamp & Time stamp of pixel containing the main platform location \\
\hline offset_vs_main & Offset (s) of time stamp relative to the main platform time stamp \\
\hline timestamp_cntr & Time stamp of pixel containing column grid center \\
\hline \multicolumn{2}{|l|}{ MRMS: $0.01^{\circ} \times 0.01^{\circ} \mathrm{QPE}$} \\
\hline timestamp & Time stamp of the MRMS QPE product \\
\hline offset_vs_main & Offset (s) of time stamp relative to the main platform time stamp \\
\hline \multicolumn{2}{|l|}{ Radiosondes: Level 4 data } \\
\hline launch_[latitude], [longitude], [elevation] & Launch site latitude, longitude, and elevation \\
\hline sonde_[latitude], [longitude], [altitude] & $\begin{array}{l}\text { Sonde sensor latitude, longitude, and altitude at each original } \\
\text { sounding vertical level }\end{array}$ \\
\hline launch_timestamp & Time stamp of sounding observations (sonde launch time) \\
\hline offset_vs_main & Offset (s) of time stamp relative to the main platform time stamp \\
\hline
\end{tabular}

University, including attenuation correction and computation of specific differential phase $\left(K_{\mathrm{dp}}\right)$ at $\mathrm{Ku}$ band (R. Beauchamp and V. Chandrasekar 2016, personal communication). Each of these scanning radars are available in the WPRF sampling domain, which was the initial target domain for SIMBA. An additional groundbased scanning radar module supports observations from the National Science Foundation's dual-polarimetric Doppler On Wheels (DOW; Wurman et al. 1997), an $\mathrm{X}$-band radar deployed in OLYMPEX. Input DOW data are in netCDF format (single volume per file) and have undergone an initial filtering, correction of a known differential reflectivity offset, and the computation of the specific differential phase (Petersen et al. 2018). Available fields for each of these radars are noted in Table 1.

Ground-based scanning radar observations are set into the SIMBA column grid through the use of NCAR's Radx software (http://www.eol.ucar.edu/software/radx). For each available ground radar data volume, SIMBA generates a Radx2Grid instruction file using NCAR's Table-Driven Runtime Parameter (TDPR) convention 
TABLE 3. Summary of gridding parameters used for ground-based scanning radars.

\begin{tabular}{|c|c|c|c|c|}
\hline Radar type & $\begin{array}{l}\text { Grid center and } \\
\text { spacing }\end{array}$ & Full grid extent (km) & $\begin{array}{l}\text { Select Radx TDRP gridding } \\
\text { parameters }\end{array}$ & $\begin{array}{l}\text { Gridding step input/output } \\
\text { format }\end{array}$ \\
\hline NPOL & $\begin{array}{l}\text { User-defined SIMBA } \\
\text { column grid center }\end{array}$ & $\begin{array}{l}\text { Horizontal: } \pm 100 \\
\text { Vertical: } 15\end{array}$ & $\begin{array}{l}\text { interp_mode: INTERP_ } \\
\text { MODE_CART }\end{array}$ & $\mathrm{UF} /$ netCDF \\
\hline NEXRAD & $\begin{array}{l}\text { location, and horizontal } \\
\text { and vertical grid spacing }\end{array}$ & $\begin{array}{l}\text { Horizontal: } \pm 100 \\
\text { Vertical: } 15\end{array}$ & min_valid_for_interp: 3 & $\mathrm{UF} /$ netCDF \\
\hline D3R & & $\begin{array}{l}\text { Horizontal: } \pm 40 \\
\text { Vertical: } 15\end{array}$ & $\begin{array}{l}\text { use_fixed_angle_for_ } \\
\text { interpolation: FALSE }\end{array}$ & netCDF/netCDF \\
\hline DOW & & $\begin{array}{l}\text { Horizontal: } \pm 60 \\
\text { Vertical: } 15\end{array}$ & $\begin{array}{l}\text { beam_width_fraction_for_ } \\
\text { data_limit_extension: } \\
\text { generally } 0.5(1.0) \text { for PPI } \\
\text { (RHI) }\end{array}$ & netCDF/netCDF \\
\hline
\end{tabular}

(http://www.ral.ucar.edu/projects/titan/docs/tdrp/). Specific gridding parameters used for each ground radar and scan type are summarized in Table 3. SIMBA modules for each type of ground-based scanning radar execute Radx to grid the radar volume to a full grid with an identical center location and horizontal and vertical grid spacing as the SIMBA column grid. Total vertical extent of the full grid is set to $15 \mathrm{~km}$, and total horizontal extent is based on the maximum range of the radar. For GPM GV quality-controlled data (NPOL and NEXRAD), the discrete hydrometeor identification (ID) values (HID in Table 1) are set into the new grid via a nearest neighbor approach. Data fields for each ground-based scanning radar are presently set within respective modules (following the lists in Table 1); a future version may permit a user-specified subset of fields to be gridded and included in the output column file. The subset of data within the user-defined column grid is then extracted from the full grid Radx output. SIMBA currently does not adjust multiple input radar frequencies to a common reference, though this is planned for future inclusion, and other than the quality control processing mentioned above, SIMBA does not apply further corrections to the ground-based scanning radar data.

In addition to the ground-based scanning radars, the WPRF includes several NASA-owned vertically profiling Micro Rain Radars (MRRs), which are also deployed in numerous GPM GV campaigns. Peters et al. (2005) provide details on the MRR instrument, and we note that these sensors have been used in a variety of precipitation studies, for example, multiradar consistency and rainfall-reflectivity $(Z-R)$ relationships (Tokay et al. 2009), DSD characteristics (Harikumar et al. 2012; Adirosi et al. 2016), spatial rainfall variability (Chen et al. 2015), and lake-effect snowfall (Minder et al. 2015). SIMBA input MRR data have been processed by vendor-provided (METEK) software and include averages of moments and parameters computed from several spectra; the NASA MRRs generally use a $60-\mathrm{s}$ averaging interval (M. Wingo 2017, personal communication). The MRR module computes profiles of the mass-weighted mean diameter $\left(D_{M}\right)$ and the normalized intercept parameter $\left(N_{W}\right)$ for a normalized gamma drop size distribution, following Testud et al. (2001). Profiles are then resampled from the native MRR vertical resolution to match the vertical levels in the SIMBA column grid. Provided the original MRR unit location is within the horizontal bounds of the user-specified column grid, resultant profiles for each MRR field noted in Table 1 are placed at the horizontal column grid location nearest to the unit location. The original MRR unit location and the radar gate size are preserved in the column file attributes. As with NEXRAD, SIMBA allows the input of data from multiple MRR units at the same time, helpful when several MRR instruments are deployed within a local study area.

SIMBA also takes in observations collected with a variety of disdrometers and rain gauges. Input files for 2D video disdrometers (2DVDs), laser optical Particle Size and Velocity (Parsivel) disdrometers, Pluvio weighing rain gauges, and traditional tipping-bucket gauges have undergone quality control processing at Goddard Space Flight Center using previously documented methods (Tokay et al. 2001; Wang et al. 2008; Tokay et al. 2013) and contain fields as indicated by Table 1 . These quality-controlled data, available at a 1-min interval, are used as SIMBA input (no further direct processing is applied to the disdrometer or gauge data). Presently, SIMBA includes disdrometer and gauge data at only the 1-min time stamp matching the main platform time stamp (described below) in the new column file; a forthcoming version will also include values over a user-specified time interval relative to the main platform time stamp. Separate SIMBA modules for each disdrometer and gauge type read the data, identify platform locations, and set the available values to the nearest horizontal column grid location. Data from multiple disdrometer and rain gauge units can be input simultaneously. The original exact locations of each 
unit are preserved as attributes in the new atmospheric column data file.

Data from the GPM Core Observatory's GMI and DPR are processed and made available by NASA's Precipitation Processing System (PPS; http://pps.gsfc.nasa.gov). SIMBA input for space-based GPM observations are Hierarchical Data Format, Release 5 (HDF5), format PPS products. Modules for each GPM product noted in Table 1 locate the pixel(s) containing SIMBA column grid points within the swath data. For each SIMBA column grid point, the pixel values at that location are assigned to the new column grid data structure. No horizontal interpolation or smoothing of the pixel values is done in SIMBA. This provides a better evaluation of subpixel-scale variabilities revealed by the gridded ground-based and finer-spatial-resolution data against the results of the various satellite product algorithms. At present, Level 1C (L1C) calibrated GMI (GSFC 2017a), Level 2A GPROF (L2AGPROF) GMI (Kummerow et al. 2015; GSFC 2017b), and Level 2A DPR (L2ADPR; Iguchi et al. 2017) products in data versions 04A and 05A are supported. The L1C module returns the calibrated brightness temperatures at each GMI channel and the incidence and sun-glint angles. The GPROF GMI module returns fields that have been derived from an analysis of the L1C data by the GPROF algorithm, including surface precipitation rate and total precipitable water, as well as rain, cloud, and ice water paths. Depending on the PPS data version, GPROF fields representing liquid or frozen and convective precipitation at the surface are also available in the PPS product and are included in the SIMBA output. The 2ADPR data include radar reflectivity, rain rate, attenuation components, brightband characteristics, total precipitable water, and derived DSD parameters within the Ku-band [normal scans (NS)] and Ka-band [high sensitivity scans (HS)] scan swaths, with vertical resolutions of 125 and $250 \mathrm{~m}$, respectively. Most of these fields are also available in the $125-\mathrm{m}$ verticalresolution-matched $\mathrm{Ku}-/ \mathrm{Ka}$-band [matched scans (MS)] scan swath. No values below the height of the DPR's lowest clutter-free bin are included in SIMBA. Continued module development is underway for additional PPS GPM products, including the combined Level 2B GMI and DPR precipitation retrievals (L2BCMB; Grecu et al. 2016; Olson et al. 2016) as well as the L1C common intercalibrated brightness temperatures and 2AGPROF retrievals from the GPM constellation partner sensors.

Thermodynamic soundings are also supported in SIMBA. Written to include soundings collected in the OLYMPEX campaign (section 4), this module presently reads in sounding data that have undergone both objective quality control and a visual inspection and have been set to a uniform vertical resolution $(5 \mathrm{hPa})$, following the procedure described by Ciesielski et al. (2012). While multiple types of sondes were used in OLYMPEX, these Level 4 sounding data ensure a consistent input format for all launch sites; the sondes module performs no other quality control on these input data. Profiles of temperature, dewpoint, and wind speed and direction for the sounding nearest to the main platform time stamp (see below) are resampled to match the column grid's vertical spacing. Derived parameters, such as the lifting condensation level, convective available potential energy (CAPE), and precipitable water, are typically also available in the Level 4 sounding data and are included in the new column file (Table 1). Sounding profiles are placed at the horizontal column grid location nearest to the sounding launch site location. Attributes maintained in the SIMBA output are noted in Table 2 and include the exact location of the sonde launch site, launch time, and the original sonde position information (latitude, longitude, and altitude of the sensor for each original observation level). The use of a 3D interpolation scheme is being explored so that horizontal sonde motion during balloon ascent will be better accounted for in a forthcoming version of this module.

In addition to the aforementioned data platforms, SIMBA also includes a module for MRMS QPE products. If there are GPM DPR data in the column, then the MRMS time nearest to the DPR time (timestamp_cntr in Table 2) is identified (if the GPM DPR is not available, then the main platform time stamp, described below, is used). Spatially, SIMBA locates the $0.01^{\circ} \times 0.01^{\circ}$ MRMS points nearest to each of the column grid points and extracts values for surface precipitation, precipitation type, the MRMS radar quality index, and the ratio of hourly rain gauge-adjusted precipitation rates to hourly radar-only precipitation rates (when available). It is presently assumed that the user-defined horizontal column grid spacing will be on the order of $0.5-1.0 \mathrm{~km}$, and MRMS values are assigned directly to the column grid points.

\section{b. Additional SIMBA components}

Along with the suite of platform-specific modules, additional SIMBA functions and procedures handle a host of other tasks. Execution of the system begins in the main SIMBA procedure; this includes user definition of the column grid by setting the location for the grid center, total horizontal and vertical extent, and the horizontal and vertical column grid spacing. While such flexibility is a key aspect of SIMBA, it requires user mindfulness, principally for defining the column grid spacing in a reasonable way based on input datasets (e.g., setting a horizontal grid spacing significantly 
smaller than the gate size of the ground-based scanning radars would not be a wise practice). Generally, we recommend SIMBA column grid spacing be set to at least $500 \mathrm{~m}$ in the horizontal and at least $250 \mathrm{~m}$ in the vertical planes, and we note that for some applications larger grid spacing on the order of $1 \mathrm{~km}$ may be more relevant (e.g., comparisons of ground-based radar and satelliteborne passive and active microwave observations at the pixel scale or evaluating numerical model output). Since a primary motivator for SIMBA development pertains to subfootprint-scale variabilities, the column grid total horizontal extent is typically set at 5, 10,15 , or $20 \mathrm{~km}$ (corresponding to the approximate size of GPM DPR and GMI pixels). However, the system can support larger column grids (as might be used, following the previous examples, for pixel-scale evaluations and/or numerical model output assessment). Prior to the ground-based scanning radar module gridding the data from each radar, a SIMBA function creates the Radx2Grid TDRP instruction file based on the radar type, user-defined column grid parameters, and scan mode (Table 3).

Attribute functions parse key parameters from data files and/or their headers to preserve this information in the new column file. Table 2 lists the attributes maintained for each platform. Regardless of platform type, original data time stamps and site location (for the ground-based instruments) are kept in these attributes. Additional sensor-specific parameters are included, particularly for spaceborne instruments and groundbased radars.

While all values written to SIMBA's atmospheric column data files are spatially coincident, this is not always the case temporally. Differences in observation times arise primarily as a result of the very rapid movement of satellite-based sensors and challenges in exactly syncing ground-based radar scan times. To handle this, SIMBA input files are chosen to be as closely matched in time as possible, and the framework takes great care to preserve observation time offset information. Prior to SIMBA execution, in addition to the column grid parameters (center location, spacing, and total extent), the user must select a "main" platform. At present, the main platform must be a ground-based radar. SIMBA uses the time stamp of the main platform's input data file as the time stamp of the output atmospheric column file. Offset values (recorded as number of seconds) relative to the main platform time stamp are maintained as attributes for every platform. For satellite-based sensors, the scan time of the pixel containing the main platform location is used. An additional time stamp attribute is also included for spaceborne sensors: the scan time of the pixel containing the SIMBA column grid center point.
After SIMBA has identified the data attributes for each platform and set available observations to the userdefined column grid, SIMBA's writing procedure creates the new netCDF atmospheric column data file. Once SIMBA has been executed and this file exists, an additional utility can be invoked to create an inventory list and a simple map image showing the location of the column grid box and available platforms (examples from the first case study below are included in the supplemental material).

\section{c. Dependencies}

The SIMBA precipitation data fusion software architecture is maintained at Marshall Space Flight Center. SIMBA is written in IDL and utilizes additional tools common in the radar and satellite communities. The packaged library of SIMBA code is freely available from NASA, though executing the system requires an IDL license. With its GV motivation, SIMBA was conceived in part to serve as a complimentary system to the GPM GV VN, which also relies on IDL. Once generated, the SIMBA atmospheric column data file can be used in any setting supporting netCDF files. In the spirit of Heistermann et al. (2015), the conversion of SIMBA to a more open environment [i.e., Python and/or GNU Data Language (GDL)] is being considered for the future, with primary porting concerns centered on utility libraries (see below) and full GDL-IDL compatibility.

The Radar Software Library in IDL (RSL in IDL; Wolff and Kelley 2009) is a set of freely provided utilities originally developed in $\mathrm{C}$ for working with NASA TRMM GV radar data (https://trmm-fc.gsfc.nasa.gov/ trmm_gv/software/rsl_in_idl/RSL_in_IDL.html). SIMBA uses RSL in IDL to extract radar specifications and scan parameters for preservation as attributes. As mentioned in section 2a, gridding of ground-based scanning radar data to Cartesian coordinates is done via NCAR's Radx software (http://www.eol.ucar.edu/software/radx). An additional library, initially written for use in the GPM GV VN, is used for reading in the GPM PPS satellite products; components of this library used by SIMBA are provided in the SIMBA package.

\section{d. SIMBA output: An atmospheric column data product}

SIMBA generates a new atmospheric column data product. This netCDF file includes all available data from the SIMBA-support platforms (Table 1) set into a common user-specified 3D grid defining the atmospheric column. SIMBA does not create new data fields computed from the various data sources but rather provides a spatially concomitant set of multiplatform observational fields throughout the user-defined column 
(a)

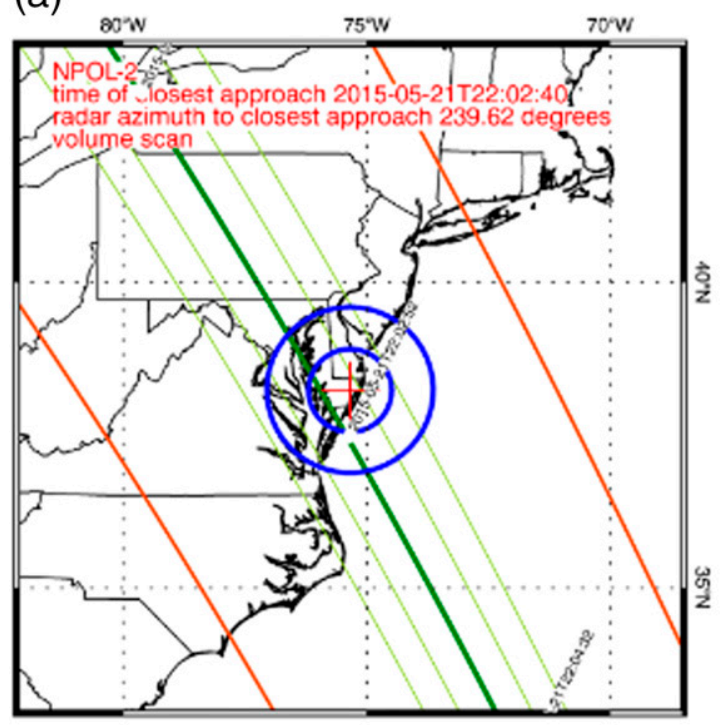

(b)

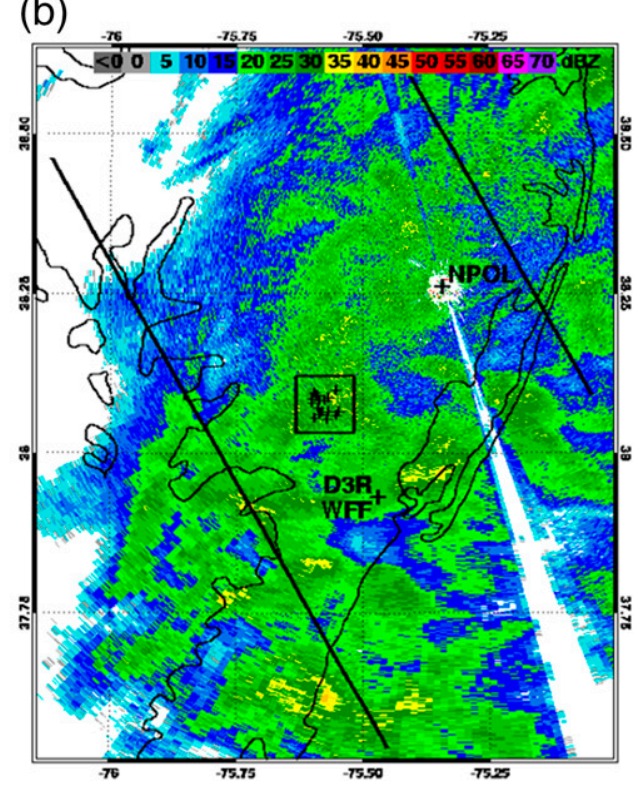

FIG. 2. Overview of 21 May 2015 WPRF GPM overpass case. (a) Regional view of GPM GMI (red) and DPR (green) swath lines over NPOL (red cross; 75- and 150-km range rings in blue). (b) Map showing placement of SIMBA column grid over WPRF's collection of rain gauges (crosses) near Pocomoke City with $1.2^{\circ}$ NPOL reflectivity at 2205 UTC. Paths of nadir and northeastmost row of GPM DPR Ka-band scans (black lines).

grid. In this way, SIMBA is a unique precipitation data fusion tool. If data from a supported platform are not available, then no fields for that sensor (right column in Table 1) are included in the SIMBA output file and attributes will indicate the platform is unavailable. Table 1 lists all platforms presently supported in SIMBA, and continuing work to support additional sensors and products is ongoing. Platform-specific parameters are preserved as attributes in the SIMBA output file (Table 2). An example SIMBA atmospheric column file is provided in the supplemental material and is used in the first example case study below.

\section{e. Supporting additional platforms}

New modules can be added to SIMBA to incorporate observations from other platforms or datasets not currently supported, provided the data structure format used within the system is followed. Documentation files included with the system detail each SIMBA component and module as well as the data structures used in generating the new column file. Adding support for an additional groundbased scanning radar, for example, would require these basic steps: Retrieval of the platform attributes from the new input data will be added to the attribute setting function. Specifications for gridding the new radar data via Radx will be added to the TDRP generation procedure. A new module will be created to set the data into the column grid data structure, following the form of existing modules and the data structure detailed in the SIMBA documentation. Finally, the column file writing procedure will be amended to include values from the newly added data structure in the output column file. This process can be modified as appropriate for other platform types (e.g., if not a ground-based scanning radar, the TDRP generation procedure does not need modification).

\section{Demonstration of SIMBA for analysis of an event observed at the NASA WPRF}

On 21 May 2015, widespread precipitation occurred over the WPRF region as a developing surface low traversed eastern North Carolina and approached the southern tip of the Delmarva Peninsula. Figure 2a shows the path of the GPM Core Observatory as it made a descending pass over the area, making its closest approach to the Newark, Maryland, NPOL site at about 2203 UTC. Figure $2 \mathrm{~b}$ gives the $1.2^{\circ}$ elevation PPI scan of NPOL equivalent reflectivity factor $\left(Z_{e}\right)$ near this time. WPRF maintains a $5 \mathrm{~km} \times 5 \mathrm{~km}$ array of tipping-bucket rain gauge pairs near Pocomoke City, Maryland, centered roughly $18.5 \mathrm{~km}$ northwest of Wallops Flight Facility (WFF) or about $30 \mathrm{~km}$ southwest of NPOL (shown as crosses in Fig. 2b). The approximately 5-km resolution of the GPM DPR (Hou et al. 2014) served as a motivator for the $5 \mathrm{~km} \times 5 \mathrm{~km}$ design of the Pocomoke instrument array. For this example, we will focus on 
TABLE 4. Platforms available in the 2205 UTC SIMBA atmospheric column file for the 21 May 2015 WPRF case. For the GMI and DPR, M (C) indicates the time stamp of the pixel containing the main platform (column grid center location). Because the WFF 2DVDs and MRR observations are not located in the example column grid (Pocomoke gauge network area; see Fig. 2b), SIMBA does not include these platforms in the atmospheric column data file, and they are not listed in the table. Figure 3 is generated from only this atmospheric column file. VCP: volume coverage pattern.

\begin{tabular}{|c|c|c|c|c|}
\hline \multicolumn{5}{|c|}{21 May 2015 WPRF 2205 SIMBA column file } \\
\hline \multicolumn{5}{|c|}{ Centered on: Pocomoke gauge network } \\
\hline \multicolumn{5}{|c|}{ Total extent, spacing: $10 \mathrm{~km} \times 10 \mathrm{~km} \times 5 \mathrm{~km}, 500 \mathrm{~m}$} \\
\hline Platform & Location & Time stamp & $\begin{array}{l}\text { Offset relative to main } \\
\text { platform (NPOL) time } \\
\text { stamp (s) }\end{array}$ & Description \\
\hline NPOL & Newark, MD & 220534 & 0 & 3-tilt PPI scan \\
\hline D3R & WFF & 220659 & 85 & 8-tilt PPI scan \\
\hline KDOX & Dover, DE & 220400 & -94 & VCP 21 PPI scan \\
\hline KAKQ & Wakefield, VA & 220318 & -136 & VCP 12 PPI scan \\
\hline Parsivel & WFF, Pocomoke Array & 2205 & $0^{\mathrm{a}}$ & 1 unit \\
\hline Rain gauge & WFF, Pocomoke Array & 2205 & $0^{\mathrm{a}}$ & 15 pairs of units \\
\hline \multirow[t]{2}{*}{ GMI } & GPM Core Observatory & $220349(\mathrm{M})$ & -105 & V05A, L1C, and L2AGPROF \\
\hline & & $220351(\mathrm{C})$ & -103 & \\
\hline \multirow[t]{2}{*}{ DPR } & GPM Core Observatory & $220242(\mathrm{M})$ & -172 & V05A, L2ADPR \\
\hline & & $220243(\mathrm{C})$ & -171 & \\
\hline MRMS & CONUS & 220200 & -214 & $0.01^{\circ} \times 0.01^{\circ}$ gridded \\
\hline
\end{tabular}

${ }^{\mathrm{a}}$ Input data are at 1-min intervals.

precipitation rate variability at the subpixel scale from the GPM DPR, NPOL, and WPRF's Pocomoke rain gauge array. A SIMBA column grid is centered over the gauge array, set to extend $10 \mathrm{~km} \times 10 \mathrm{~km} \times 5 \mathrm{~km}$ in the horizontal and vertical with a spacing of $500 \mathrm{~m}$ in all directions. The $10-\mathrm{km}$ horizontal extent is chosen so the output column file will include the entire gauge array and a buffer area for additional context. NPOL is assigned as the main platform.

In addition to observations from the Pocomoke gauge array and a Parsivel disdrometer within the array, data are available within the column grid from the NASA NPOL and D3R, as well as the Dover, Delaware, and Wakefield, Virginia, NEXRAD. Additional WPRF data exist for this day (i.e., MRR, 2DVDs, and other Parsivels), but only observations located within the column grid (box in Fig. 2b) are included in the SIMBA output file. Table 4 lists the inventory of platforms available in the SIMBA column file over the Pocomoke array for this event (information in Table 4 is similar to the SIMBA column file header). The selected ground-based radar scans have time stamps (start of volume scan) as near to the time of the GPM Core Observatory overpass as possible. The NPOL scan nearest to the overpass time is a PPI/surveillance scan with three elevation angles $\left(0.7^{\circ}, 1.2^{\circ}\right.$, and $\left.1.7^{\circ}\right)$. Values in this 2205 UTC column file are presented as the spatial views in Fig. 3.

Across the $5 \mathrm{~km} \times 5 \mathrm{~km}$ Pocomoke array, NPOL $Z_{e}$ at $500 \mathrm{~m}$ AGL ranges from 20 to $35 \mathrm{dBZ}$, with larger values generally toward the northeast (Fig. 3). Such a gradient is also evident in the NPOL-derived rain-rate field (Fig. 3b), with peak values approaching $10 \mathrm{~mm} \mathrm{~h}^{-1}$ occurring in the northeastern Pocomoke network. While the rain rates measured by the rain gauges and Parsivel are overall higher than those derived from NPOL across the domain (about $8 \mathrm{~mm} \mathrm{~h}^{-1}$ over the entire array), the minimum values occur to the southern and western edges of the domain (the two southernmost sites at 6.0 and $5.4 \mathrm{~mm} \mathrm{~h}^{-1}$ and the two westernmost gauges at 6.0 and $7.0 \mathrm{~mm} \mathrm{~h}^{-1}$ ); however, peak rain rates from the gauges are located in the south-central portion of the array (mean near $9.0 \mathrm{~mm} \mathrm{~h}^{-1}$ for the three highestreporting units). MRMS rain rates (yellow contours every $0.5 \mathrm{~mm} \mathrm{~h}^{-1}$ ) show an opposite gradient than NPOL, with about $2 \mathrm{~mm} \mathrm{~h}^{-1}$ in the northeastern portion of the instrument array and just over $5 \mathrm{~mm} \mathrm{~h}^{-1}$ at the southwestern edge. These variabilities exist within the scale of the GPM GMI and DPR observations (about 15 and $5 \mathrm{~km}$, respectively). Over the entire Pocomoke array, GMI GPROF indicates $1.56 \mathrm{~mm} \mathrm{~h}^{-1}$, while the DPR MS (matched beam scan for DPR's Ku and Ka bands) gives $2-5 \mathrm{~mm} \mathrm{~h}^{-1}$ over the majority of the area. Thus, while both space-based estimates of rain intensity are less than that observed with the Pocomoke ground instruments, the DPR MS result compares reasonably well with the NPOL-derived values. We note that the agreement of the DPR MS at the subsequent NPOL volume time is slightly better: for 2211 UTC, the mean rain rate observed by the Pocomoke gauges and Parsivel is about $5.6 \mathrm{~mm} \mathrm{~h}^{-1}$ (not shown). The DPR MS 

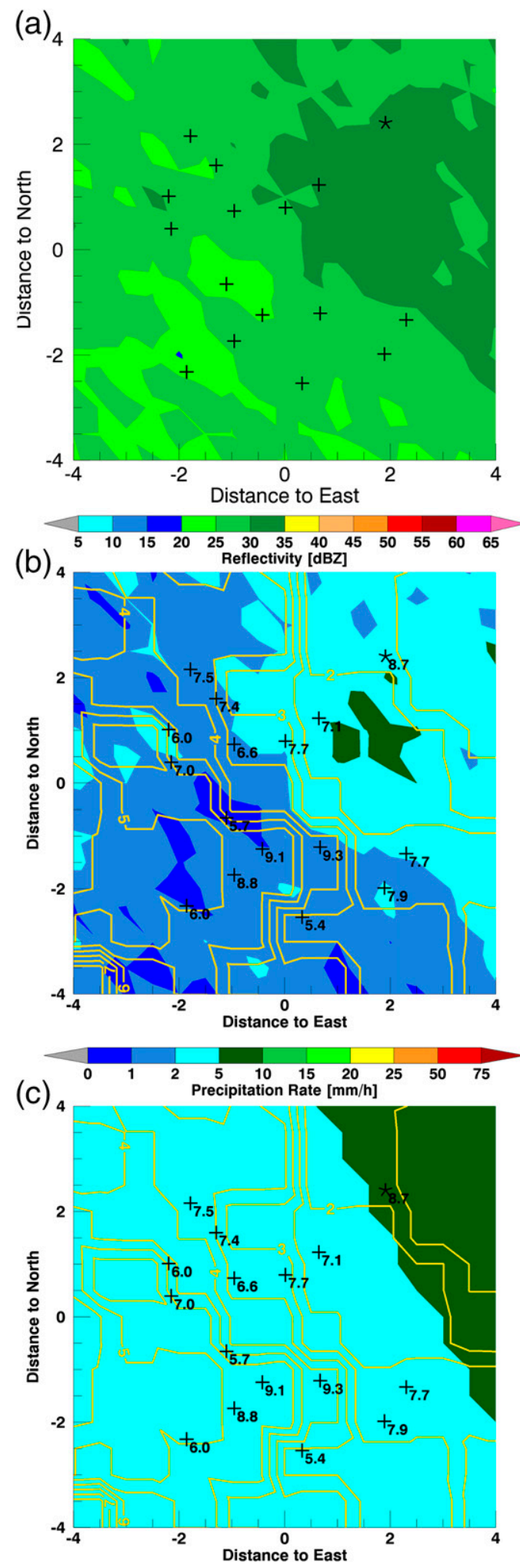

FIG. 3. Plots from 2205 UTC SIMBA column file for 21 May 2015 WPRF case: (a) NPOL reflectivity at $500 \mathrm{~m}$ AGL, (b) NPOL-derived rain rate (Chen et al. 2017) at $500 \mathrm{~m} \mathrm{AGL}$, and (c) DPR Ka-/Ku-matched beam surface precipitation rate. Panels (b) and (c) use the same color precipitation rate in Fig. 3 corresponds well to this later time of surface observation; this may be related to the time required for raindrops to actually reach the ground-a similar delay in the best agreement of gauge versus TRMM precipitation rates over southeast Arizona was noted by Amitai et al. (2012).

Spatial variability in stratiform precipitation, as in this event, can present challenges for larger-scale precipitation estimation. The SIMBA data fusion framework provides a multisensor data product well suited for examining these variabilities at the subpixel scale. A recent SIMBA-based study of precipitation rates at the WFF main base further examines the 21 May 2015 event (Pabla et al. 2017).

\section{Demonstration of SIMBA for analysis of an OLYMPEX case}

In addition to the difficulties arising from small-scale spatial variabilities in stratiform rain, our understanding of precipitation processes in areas of complex terrain remains quite limited. Over the 2015/16 winter season, the OLYMPEX field campaign collected data aimed at supporting GPM GV efforts as well as improving understanding of precipitation evolution in Pacific frontal systems traversing the coastal to high terrain transition of the Olympic Mountains and Olympic Peninsula region (Petersen et al. 2016; Houze et al. 2017). All observations collected as part of the campaign are archived at NASA's Global Hydrology Resource Center (GHRC; http://ghrc.nsstc.nasa.gov; Petersen et al. 2018). From a GPM GV perspective, perhaps the best-sampled OLYMPEX event occurred on 3 December 2015, when a GPM Core Observatory overpass and exceptionally wellcoordinated airborne observations sampled an evolving baroclinic system over the domain covered by groundbased instruments. Figures 4 and 5 give an overview of this case and illustrate the extensive network of field sites, including operational and research ground-based scanning radars, profiling Doppler radars, sounding launch locations, and various rain gauge and disdrometer installations. Fortuitously, the geometry of this overpass is such that a single scan from the DPR (row of pixels with the same observation time) is in near-perfect alignment with the $230^{\circ} / 50^{\circ} \mathrm{RHI}$ from the NPOL and D3R (note the NPOL

scale. Crosses (asterisk) locate rain gauges (Parsivel disdrometer) in the Pocomoke instrument array; annotated with rain-rate values for 2205 in (b) and (c). Yellow contours in (b) and (c) show MRMS surface rain rate $\left(0.5 \mathrm{~mm} \mathrm{~h}^{-1}\right.$ interval). GMI GPROF surface precipitation rate across the entire domain $(\sim 15 \mathrm{~km}$ pixel size $)$ is $1.56 \mathrm{~mm} \mathrm{~h}^{-1}$. 
(a)

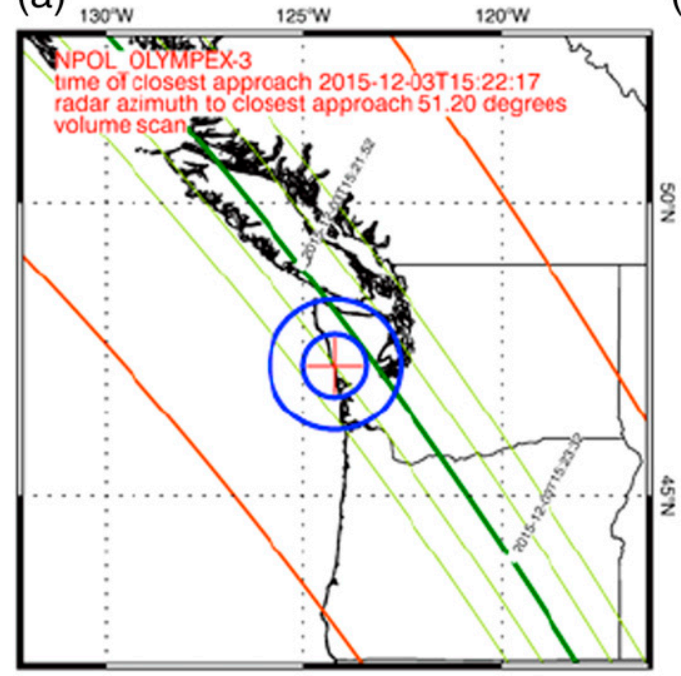

(b)

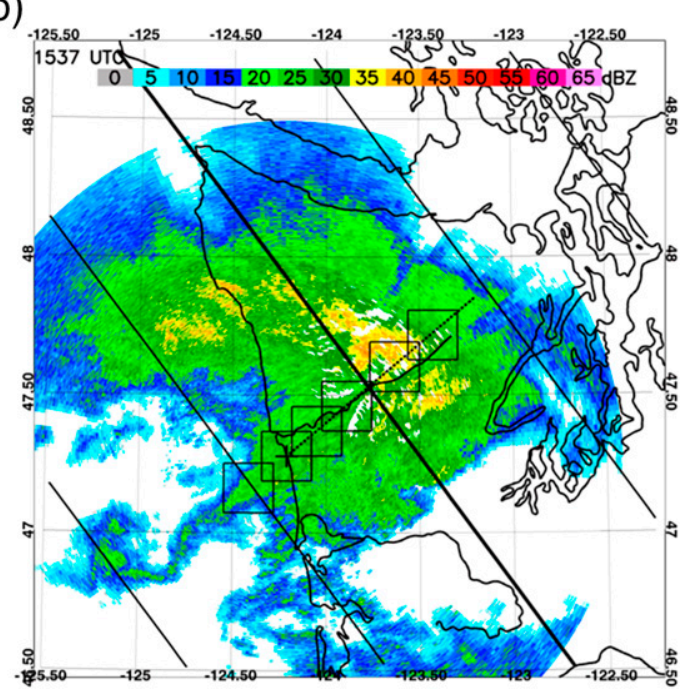

FIG. 4. Overview of 3 Dec 2015 OLYMPEX GPM overpass case. (a) Regional view of GPM GMI (red) and DPR (green) swath lines over NPOL (red cross; 75- and 150-km range rings in blue). (b) Map of $1.5^{\circ}$ NPOL reflectivity near the time of GPM overpass; dashed line shows the 50 azimuth from NPOL (cross); black lines show the paths of the DPR's nadir track (thick) and extent of the Ka- and Ku-band scan swaths (thin), and boxes locate the six SIMBA column grids $(20 \mathrm{~km} \times 20 \mathrm{~km}$ boxes $)$.

$50^{\circ} \mathrm{RHI}$ line is perpendicular to the DPR swath lines in Fig. 4b). For this example, we will consider variations in the vertical profile along this line, extending up the Quinault River Valley.

Estimating precipitation in regions of topographic variability remains a significant challenge (e.g., Germann et al. 2006; Vulpiani et al. 2012; Mei et al. 2014), but SIMBA facilitates combining the various sampling perspectives obtained during OLYMPEX to investigate such variability. Figure 6 shows the height of the lowest clutter-free DPR HS bin for this overpass. The DPR has difficulty seeing near the surface in the OLYMPEX domain, and in some locations the lowest clutter-free bin of the DPR is actually above the freezing level, as we will demonstrate below. The $50^{\circ}$ azimuth NPOL RHI scan (Fig. 7) illustrates some of the complex vertical structure during the prefrontal phase of the 3 December event, near the time of the GPM overpass. Between NPOL and the foot of the mountains, a clear bright band and vertically slanted regions of enhanced $Z_{e}$ and differential reflectivity $\left(Z_{\mathrm{dr}}\right)$ below are evident. Approaching and over the terrain, the radial velocity maximum is shifted upward, showing the impact of the terrain barrier on the flow. Near this upward shift, an enhancement in $Z_{e}$ occurs aloft (about $4.5-5 \mathrm{~km}$ ), and there is also a modest $K_{\mathrm{dp}}$ enhancement. There is evidence of a secondary $Z_{\mathrm{dr}}$ peak above the bright band, near 5-6-km height extending from 20 - to $60-\mathrm{km}$ range from NPOL (Fig. 7c). This horizontally aligned feature occurs in several OLYMPEX events and has been previously noted in Pacific frontal systems over terrain (Kingsmill et al. 2006;
Medina et al. 2007) - it is likely a manifestation of dendritic growth of horizontally oriented (hence, elevated $Z_{\mathrm{dr}}$ values) ice crystals (e.g., Kennedy and Rutledge 2011; Andrić et al. 2013; Kumjian et al. 2014a). A sounding launched from NPOL at 1516 UTC indicates temperatures of $-15^{\circ}$ to $-20^{\circ} \mathrm{C}$ at about $5.2-5.9 \mathrm{~km}$, supporting this habit type in the vicinity of the secondary $Z_{\mathrm{dr}}$ peak. A third interesting feature in $Z_{\mathrm{dr}}$ is the vertical structure with values $\geq 2.0 \mathrm{~dB}$, appearing to connect the two horizontal layers (bright band and secondary peak aloft) at a range of about $60 \mathrm{~km}$ from NPOL. At the base of this feature, $K_{\mathrm{dp}}$ is maximized to $0.6^{\circ} \mathrm{km}^{-1}$, suggesting a possible enhancement of liquid water content below, though this location is near the melting layer, which means it is possible for wet aggregates to be generating positive backscatter differential phase (e.g., Tromel et al. 2013). This vertical $Z_{\mathrm{dr}}$ feature is fairly transient; temporally, it does not appear in consecutive RHI volumes, and spatially it is evident only at adjacent azimuths for two to three scans (RHIs separated by $2^{\circ}$ ). With 20 min between NPOL RHIs over this area, it is difficult to estimate the lifetime of this feature. Its vertical structure is reminiscent of $Z_{\mathrm{dr}}$ columns observed in continental deep convective storms [e.g., Kumjian et al. (2014b), who found $Z_{\mathrm{dr}}$ columns can develop, mature, and dissipate on a time scale of 10-20 min and extend up to $3 \mathrm{~km}$ above the freezing level], but the 3 December OLYMPEX event is very different dynamically (generally isolated deep convection vs widespread prefrontal precipitation with extensive stratiform rain). Keeping in 


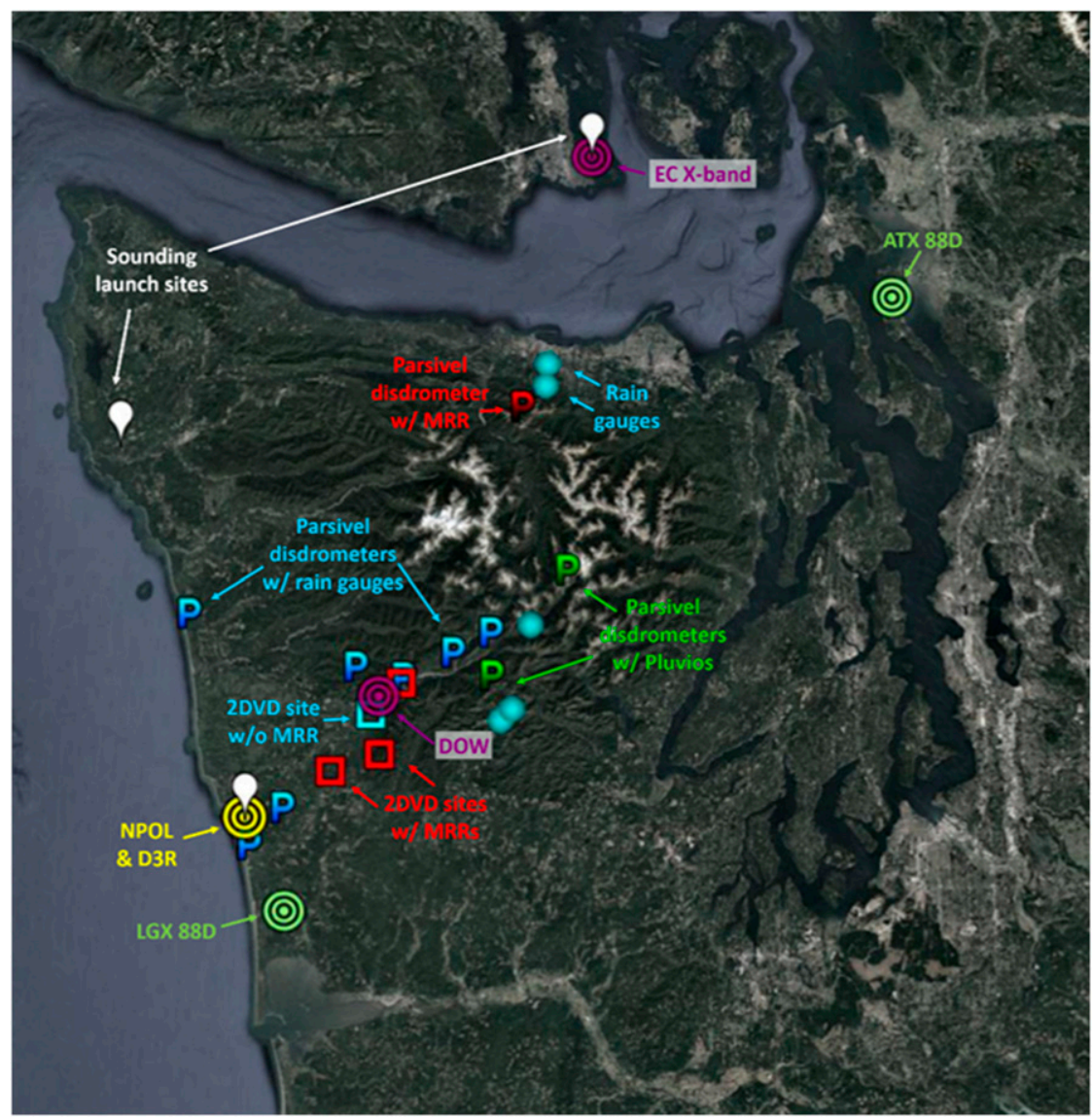

FIG. 5. Google Earth background image of the Olympic Peninsula annotated with locations of various OLYMPEX field campaign observation sites. Note for scale: the baseline from the NPOL/D3R site (yellow) to the DOW site (violet) is about $35 \mathrm{~km}$.

mind the roughly 5-km horizontal resolution of the DPR, and comparing the detailed structure seen from NPOL in Fig. 7 with the lowest clutter-free bin heights (Fig. 6), it is clear that many complexities are unobservable from the DPR. By applying SIMBA along this line, we can view the space-based observations in the same context as the more detailed, ground-based field campaign data to evaluate how well the precipitation structure is represented in the DPR data.

Table 5 provides an inventory of data available in the SIMBA column files generated for each of six sites along the NPOL $230^{\circ} / 50^{\circ}$ azimuth (information in Table 5 is similar to the SIMBA column file headers). All column grids are $20 \mathrm{~km} \times 20 \mathrm{~km} \times 6 \mathrm{~km}$ with 500 -m spacing and use NPOL as the main platform. To approximate the spatial resolution of the DPR, a $5 \mathrm{~km} \times 5 \mathrm{~km}$ area at the center of each column grid is used to obtain mean values at each vertical level. As in the previous case, a larger horizontal extent is used so the columns can include a representation of context for the $5 \mathrm{~km} \times 5 \mathrm{~km}$ focus area. Figure 8 presents profile comparisons from each column site, with each row of panels generated from a single SIMBA column file, corresponding to locations progressively farther inland up the valley. For the Midpoint (so named because it is midway between NPOL and Amanda Park, Washington) and Amanda Park sites, the MRR units are located beyond the $5 \mathrm{~km} \times 5 \mathrm{~km}$ averaging area, but as they are well within the $20 \mathrm{~km} \times 20 \mathrm{~km}$ column grid, the values are shown.

For sites with negligible terrain variation, $Z_{e}$ profiles (left panels in Fig. 8) compare reasonably well, and the DPR surface $Z_{e}$ estimates are remarkably similar to disdrometer-derived reflectivities. Farther into the valley, however, where the terrain is more complex, $Z_{e}$ profiles are expectedly more varied, and the DPR is more limited in height, unable to see at or below the freezing level for the highest elevation column site (Upper East Fork). Middle panels show profiles of rain rates derived using three algorithms (RR: Chen et al. 2017; RP: Bringi et al. 2004; RC: Cifelli et al. 2002). Again, sites at lower elevation and less 


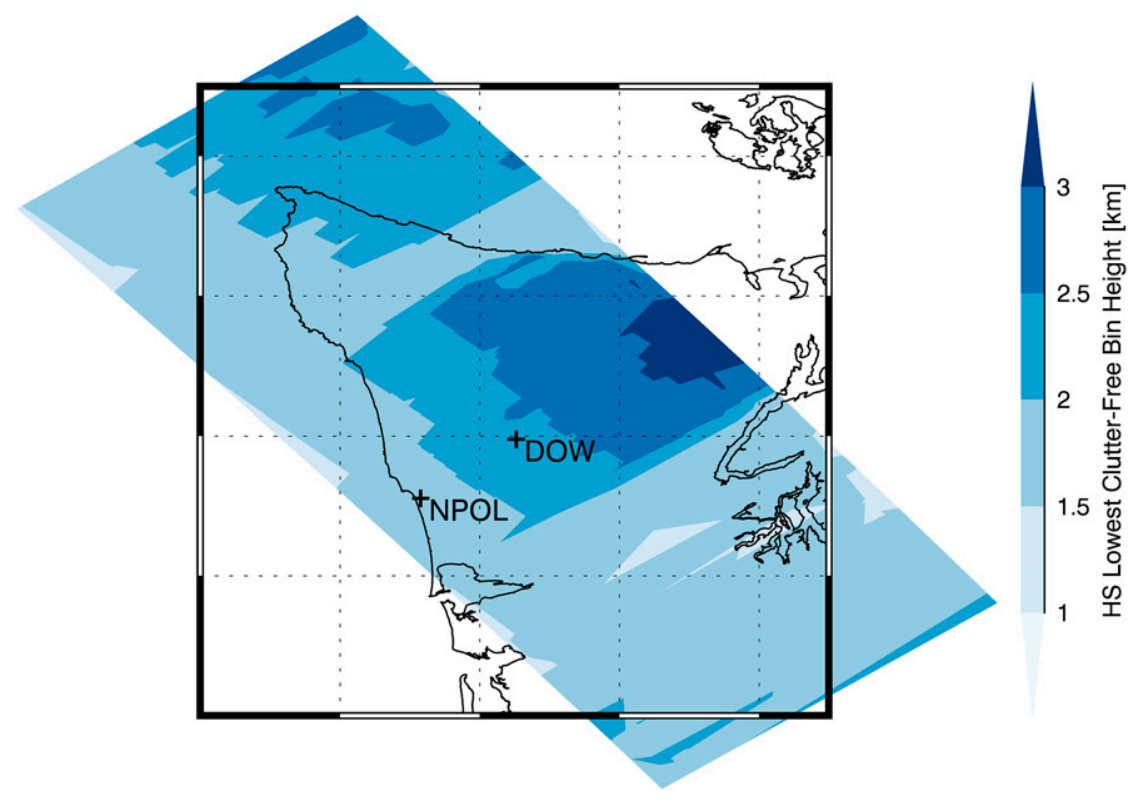

FIG. 6. Map of DPR HS lowest clutter-free bin heights for the overpass.

complex terrain show generally less variability in these profiles, particularly for the Chen et al. (2017) algorithm. Space-based surface precipitation rate estimates are within about $3 \mathrm{~mm} \mathrm{~h}^{-1}$ of the MRMS and ground instrumentation mean values at sites from the Ocean up to Amanda Park. The terrain complexity increases for the Grave's Creek and Upper East Fork sites, and at these locations the precipitation rates vary more and there is a larger discrepancy (a)

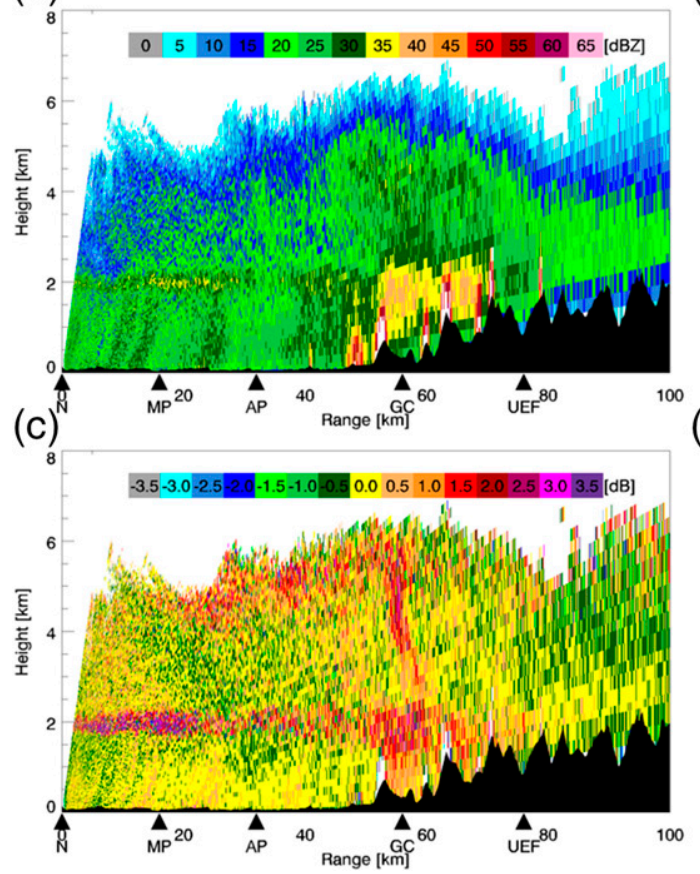

(b)

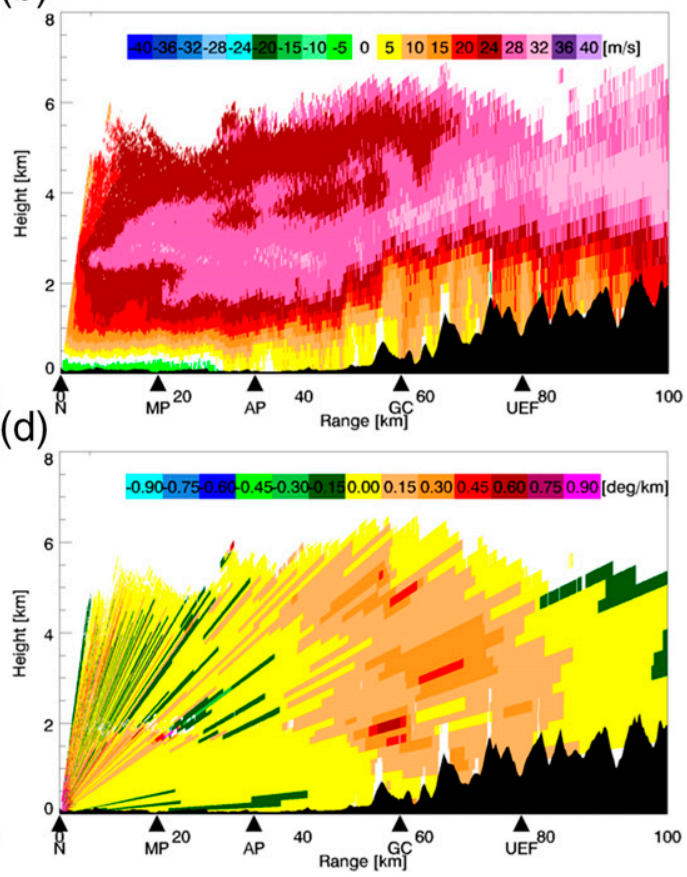

FIG. 7. The 3 Dec 2015 OLYMPEX 1532 UTC NPOL RHI at $50^{\circ}$ azimuth: (a) reflectivity, (b) velocity, (c) differential reflectivity, and (d) specific differential phase. Markers locate five of the SIMBA column grid sites: N: NPOL, MP: Midpoint, AP: Amanda Park (also approximately the DOW location), GC: Grave's Creek, and UEF: Upper East Fork. 
TABLE 5. Platforms available in SIMBA atmospheric column products for the 3 Dec 2015 OLYMPEX case. The locations of each column product in this list are shown in Fig. 5c. Elevations of the center point for each column grid are noted in parentheses. For the GMI and DPR, M (C) indicates the time stamp of the pixel containing the main platform (column grid center location). In this case, these are the same because of the nearly perfect alignment of the space-based scans with the ground-based radar RHIs. The plots in each row of Fig. 7 are generated from only one atmospheric column file.

\begin{tabular}{|c|c|c|c|c|}
\hline \multicolumn{5}{|c|}{3 Dec 2015 OLYMPEX 1520 SIMBA column file-Ocean (0 m) } \\
\hline \multicolumn{5}{|c|}{ Centered on: Ocean, $20 \mathrm{~km}$ southwest of NPOL } \\
\hline \multicolumn{5}{|c|}{ Total extent, spacing: $20 \mathrm{~km} \times 20 \mathrm{~km} \times 6 \mathrm{~km}, 500 \mathrm{~m}$} \\
\hline Platform & Location & Time stamp & $\begin{array}{l}\text { Offset relative to main } \\
\text { platform (NPOL) time } \\
\text { stamp (s) }\end{array}$ & Description \\
\hline NPOL & Near mouth of the Quinault & 152015 & 0 & $210^{\circ}-266^{\circ}$ azimuth $\mathrm{RHI}$ \\
\hline D3R & River & 151145 & -512 & $221^{\circ}-327^{\circ}$ azimuth $\mathrm{RHI}$ \\
\hline KLGX & Langley Hill, WA & 152111 & 56 & VCP 11 PPI scan \\
\hline \multirow[t]{2}{*}{ GMI } & GPM Core Observatory & $152222(\mathrm{M})$ & 127 & V05A, L1C, and L2AGPROF \\
\hline & & $152222(\mathrm{C})$ & 127 & \\
\hline \multirow[t]{2}{*}{ DPR } & GPM Core Observatory & $152332(\mathrm{M})$ & 197 & V05A, L2ADPR \\
\hline & & $152332(\mathrm{C})$ & 197 & \\
\hline MRMS & CONUS & 152400 & 225 & $0.01^{\circ} \times 0.01^{\circ}$ gridded \\
\hline
\end{tabular}

3 Dec 2015 OLYMPEX 1532 SIMBA column file-NPOL (157 m)

\begin{tabular}{|c|c|c|c|c|}
\hline \multicolumn{5}{|c|}{ Centered on: NPOL } \\
\hline \multicolumn{5}{|c|}{ Total extent, spacing: $20 \mathrm{~km} \times 20 \mathrm{~km} \times 6 \mathrm{~km}, 500 \mathrm{~m}$} \\
\hline Platform & Location & Time stamp & $\begin{array}{l}\text { Offset relative to main } \\
\text { platform (NPOL) time } \\
\text { stamp (s) }\end{array}$ & Description \\
\hline NPOL & Near mouth of the Quinault & 153223 & 0 & $30^{\circ}-60^{\circ}$ azimuth $\mathrm{RHI}$ \\
\hline D3R & River & 152449 & -454 & $30^{\circ}-60^{\circ}$ azimuth RHI \\
\hline KLGX & Langley Hill, WA & 153232 & 9 & VCP 11 PPI scan \\
\hline Parsivel & Wallace, Orchard & 1532 & $0^{\mathrm{a}}$ & 2 units \\
\hline Rain gauge & Wallace, Orchard & 1532 & $0^{\mathrm{a}}$ & 2 pairs of tipping units \\
\hline \multirow[t]{2}{*}{ GMI } & GPM Core Observatory & $152222(\mathrm{M})$ & -601 & V05A, L1C, and L2AGPROF \\
\hline & & $152222(\mathrm{C})$ & -601 & \\
\hline \multirow[t]{2}{*}{ DPR } & GPM Core Observatory & $152332(\mathrm{M})$ & -531 & V05A, L2ADPR \\
\hline & & $152332(\mathrm{C})$ & -531 & \\
\hline MRMS & CONUS & 152400 & -503 & $0.01^{\circ} \times 0.01^{\circ}$ gridded \\
\hline Sounding & Launched at NPOL & 1516 & -983 & Vaisala RS92 sonde \\
\hline
\end{tabular}

3 Dec 2015 OLYMPEX 1532 SIMBA column file-Midpoint (40 m)

\begin{tabular}{|c|c|c|c|c|}
\hline \multicolumn{5}{|c|}{ Centered on: Midpoint of NPOL and Amanda Park (16 km northeast of NPOL) } \\
\hline \multicolumn{5}{|c|}{ Total extent, spacing: $20 \mathrm{~km} \times 20 \mathrm{~km} \times 6 \mathrm{~km}, 500 \mathrm{~m}$} \\
\hline Platform & Location & Time stamp & $\begin{array}{l}\text { Offset relative to main } \\
\text { platform (NPOL) time } \\
\text { stamp (s) }\end{array}$ & Description \\
\hline NPOL & Near mouth of the Quinault & 153223 & 0 & $30^{\circ}-60^{\circ}$ azimuth $\mathrm{RHI}$ \\
\hline D3R & River & 152449 & -454 & $30^{\circ}-60^{\circ}$ azimuth RHI \\
\hline KLGX & Langley Hill, WA & 153232 & 9 & VCP 11 PPI scan \\
\hline Parsivel & Fishery & 1532 & $0^{\mathrm{a}}$ & 1 unit \\
\hline 2DVD & Fishery & 1532 & $0^{\mathrm{a}}$ & 1 unit \\
\hline Rain Gauge & Fishery & 1532 & $0^{\mathrm{a}}$ & 1 pair of tipping units \\
\hline MRR & Fishery & 1532 & $0^{\mathrm{a}}$ & 1 unit \\
\hline \multirow[t]{2}{*}{ GMI } & GPM Core Observatory & $152222(\mathrm{M})$ & -601 & V05A, L1C, and L2AGPROF \\
\hline & & $152222(\mathrm{C})$ & -601 & \\
\hline \multirow[t]{2}{*}{ DPR } & GPM Core Observatory & $152332(\mathrm{M})$ & -531 & V05A, L2ADPR \\
\hline & & $152332(\mathrm{C})$ & -531 & \\
\hline MRMS & CONUS & 152400 & -503 & $0.01^{\circ} \times 0.01^{\circ}$ gridded \\
\hline
\end{tabular}


TABLE 5. (Continued)

3 Dec 2015 OLYMPEX 1532 SIMBA column file-Amanda Park (63 m)

\begin{tabular}{|c|c|c|c|c|}
\hline \multicolumn{5}{|c|}{ Centered on: Amanda Park ( $32 \mathrm{~km}$ northeast of NPOL) } \\
\hline \multicolumn{5}{|c|}{ Total extent, spacing: $20 \mathrm{~km} \times 20 \mathrm{~km} \times 6 \mathrm{~km}, 500 \mathrm{~m}$} \\
\hline Platform & Location & Time stamp & $\begin{array}{l}\text { Offset relative to main } \\
\text { platform (NPOL) time } \\
\text { stamp (s) }\end{array}$ & Description \\
\hline NPOL & Near mouth of the Quinault & 153223 & 0 & $30^{\circ}-60^{\circ}$ azimuth $\mathrm{RHI}$ \\
\hline D3R & River & 152449 & -454 & $30^{\circ}-60^{\circ}$ azimuth $\mathrm{RHI}$ \\
\hline DOW & Amanda Park, WA & 153445 & 142 & $50^{\circ}-72^{\circ}$ azimuth $\mathrm{RHI}$ \\
\hline KLGX & Langley Hill, WA & 153232 & 9 & VCP 11 PPI scan \\
\hline Parsivel & $\begin{array}{l}\text { Prairie Creek, Norwood, } \\
\text { Amanda Park, Neilton, } \\
\text { Bishop }\end{array}$ & 1532 & $0^{\mathrm{a}}$ & 5 units \\
\hline 2DVD & $\begin{array}{l}\text { Amanda Park, Neilton, } \\
\text { Bishop }\end{array}$ & 1532 & $0^{\mathrm{a}}$ & 3 units \\
\hline Rain gauge & $\begin{array}{l}\text { Prairie Creek, Norwood, } \\
\text { Amanda Park, Neilton, } \\
\text { Bishop }\end{array}$ & 1532 & $0^{\mathrm{a}}$ & $\begin{array}{l}5 \text { pairs of tipping units, } 1 \text { Pluvio } \\
\text { unit }\end{array}$ \\
\hline MRR & Neilton, Bishop & 1532 & $0^{\mathrm{a}}$ & 2 units \\
\hline GMI & GPM Core Observatory & $152222(\mathrm{M})$ & -601 & V05A, L1C, and L2AGPROF \\
\hline & & $152222(\mathrm{C})$ & -601 & \\
\hline DPR & GPM Core Observatory & $152332(\mathrm{M})$ & -531 & V05A, L2ADPR \\
\hline & & $152332(\mathrm{C})$ & -531 & \\
\hline MRMS & CONUS & 152400 & -503 & $0.01^{\circ} \times 0.01^{\circ}$ gridded \\
\hline
\end{tabular}

3 Dec 2015 OLYMPEX 1532 SIMBA column file-Grave's Creek (358 m)

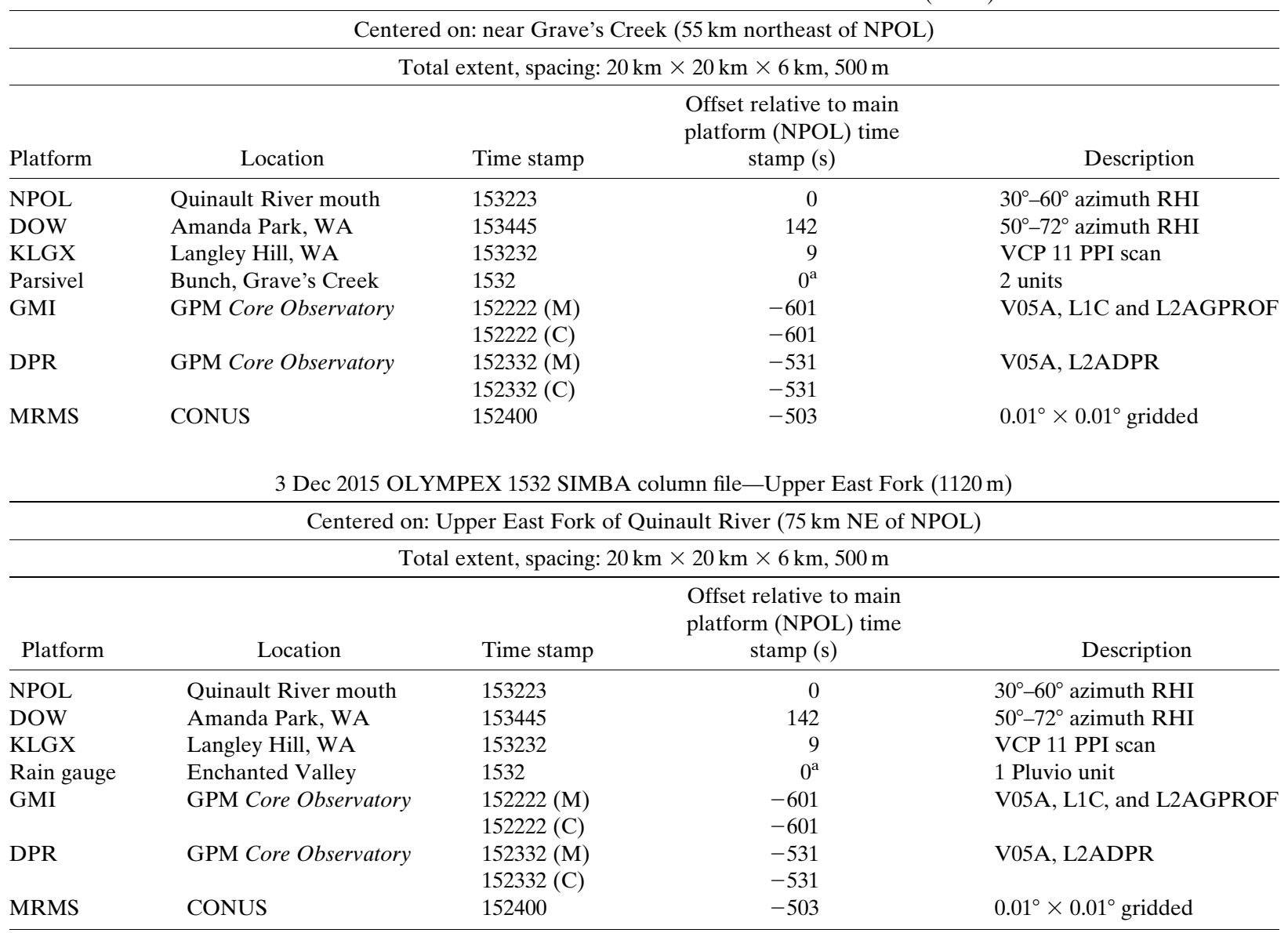

\footnotetext{
${ }^{\text {a }}$ Input data are at 1-min intervals.
} 
between the space- and ground-based values, perhaps largely owing to the fact that the lowest clutter-free bin of DPR observations is progressively higher in height over these areas.

Derived profiles of $D_{M}$ (right panels in Fig. 8) from the DPR show very little change with height compared to the $D_{M}$ profiles obtained from ground-based radars. The space-based $D_{M}$ values do not capture the variations in $D_{M}$ behavior below the melting level. At the first four sites (top four rows of Fig. 8), $D_{M}$ from the $\mathrm{S}$-band ground radars exhibit similar vertical patterns-a local maximum just below the melting level, followed by a decrease as large, newly melted drops undergo breakup (and also perhaps as snow crystals melt to small drops), then an increase in $D_{M}$ as drops fall toward the ground and presumably grow by collision and coalescence. At the other two sites farther up the valley and in more complex terrain, however, $D_{M}$ appears to behave differently below the $0^{\circ} \mathrm{C}$ level. At the Grave's Creek and Upper East Fork sites, the $D_{M}$ profile exhibits a steady decrease below the melting layer, and with the exception of KLGX (Langley Hill, Washington)'s limited coverage at Upper East Fork, there is no indication of drop growth toward the ground. In the 3 December overpass case, the prevailing flow over the study region has a strong southerly component, in large contrast to the terrain-normal flow (with a stronger westerly component) observed in several other OLYMPEX cases (Houze et al. 2017). For one of those events, 17 November 2015, Gatlin et al. (2017) show that in terrain-normal flow conditions, drops reaching the ground are characteristically larger at higher elevations. Additionally, Zagrodnik et al. (2018) demonstrate multiscale variability of precipitation regimes within the OLYMPEX storms and detail how subsynoptic storm structure appears to affect the number of larger drops observed in another case study with terrain-normal flow (12-13 November 2015). Taken together, these findings highlight the need for continued work to understand precipitation processes in complex topography. The SIMBA data fusion tool can serve as an efficient starting point for such investigations.

\section{Summary and ongoing efforts}

This paper documents the recent development of the System for Integrating Multiplatform Data to Build the Atmospheric Column (SIMBA) precipitation observation fusion framework and provides two example applications. SIMBA combines spatially coincident observations from both satellite and ground-based platforms (Table 1) onto a common 3D Cartesian grid and writes this information into a single netCDF format atmospheric column data file. Pertinent instrument specifications and operation parameters, such as microwave frequency, exact ground site location, and algorithm version, are obtained from original data files and preserved as attributes in SIMBA output (Table 2). The SIMBA framework consists of platform-specific modules and additional components that work together to interpolate, locate, and/or resample concomitant measurements to the user-defined column grid and produce a value-added product that summarizes the atmospheric column. Though it relies on the commercially available IDL, SIMBA is a freely available packaged library of code available from NASA (https://gpm-gv. gsfc.nasa.gov/SIMBA). The NASA GHRC Distributed Active Archive Center (DAAC) is working to archive pregenerated SIMBA atmospheric column data product files for select GPM field campaign events (H. Conover and D. Smith 2018, personal communication), and we note that a future conversion of SIMBA to a more open environment (i.e., Python) is being considered.

SIMBA streamlines several often tedious first steps in precipitation research. It is common practice among researchers in the radar, satellite, and precipitation science communities to develop their own (or use team/ group specific) programs suited to handling various data platforms, formats, and coordinate systems. This results in multiple scientists using separate codes (or worse, spending time to independently "reinvent the wheel") to perform very similar or identical jobs required for initial research tasks. Key benefits of the SIMBA data fusion framework will be more efficient precipitation research and promotion of result reproducibility without requiring scientists to individually perform similar tasks in their own separate code. SIMBA provides a unified framework for these initial tasks and gives precipitation researchers a convenient starting point for multiplatform investigations.

Two GPM Core Observatory satellite overpass examples were shown to demonstrate the initial utility of SIMBA. For 21 May 2015, a SIMBA atmospheric column file over a network of rain gauges during a stratiform event over the eastern shore of Virginia and Maryland demonstrated the utility of the framework as a tool for evaluating variability at the subpixel scale to assess the performance of algorithms used with the spaceborne measurements. Ground-based and GPM satellite observations from the 3 December 2015 GPM GV OLYMPEX field campaign case illustrate some of the challenges inherent to estimating precipitation from space, especially in regions of complex topography. Applying SIMBA to this OLYMPEX event shows its potential as a tool for facilitating efficient precipitation process studies.

Ongoing work to improve SIMBA is focused on supporting additional platforms and data products, and 

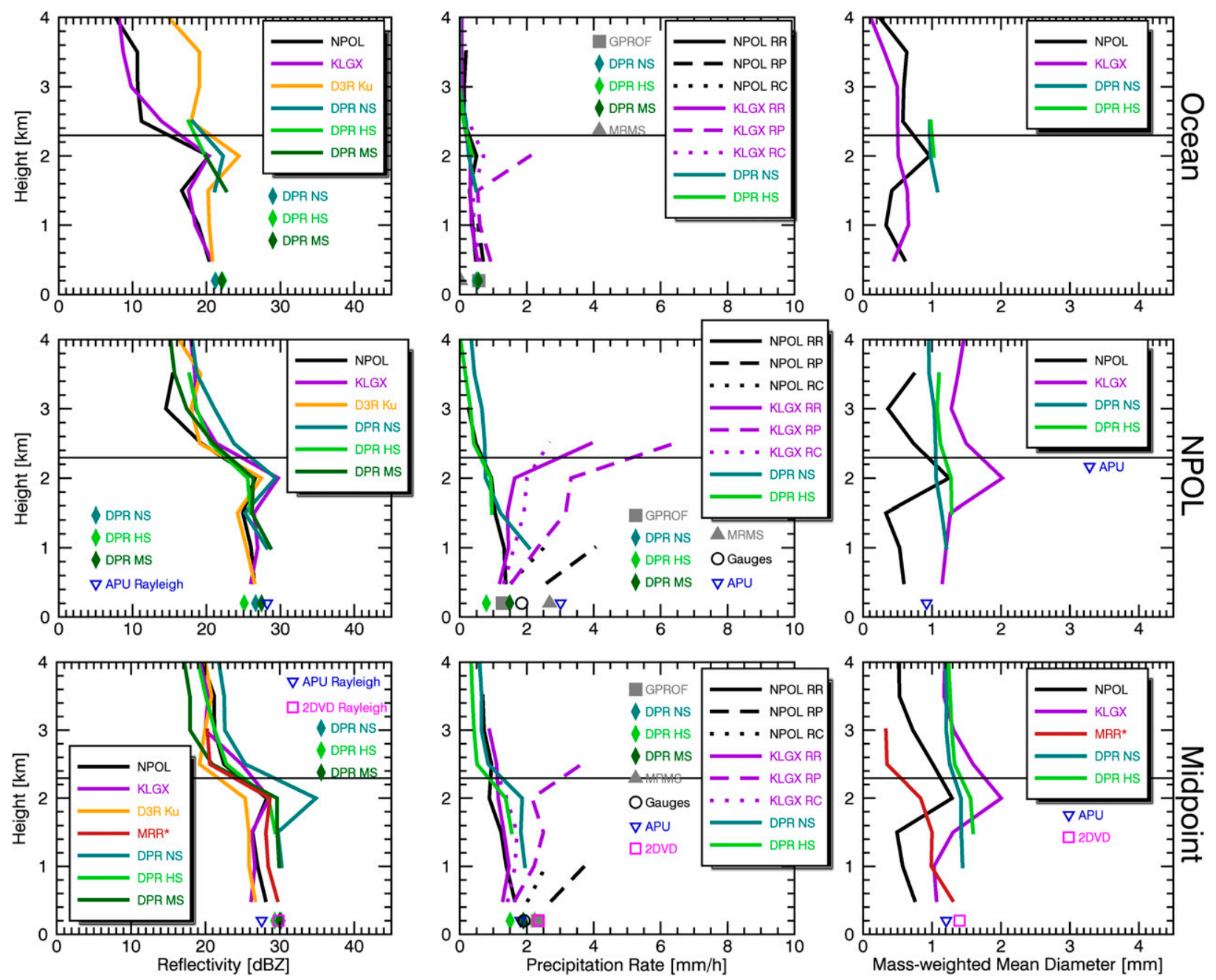

FIG. 8. Mean profiles from various platforms for each column site (labels to right) in the 3 Dec 2015 OLYMPEX case. Each profile line color corresponds to the platforms indicated in the legends. All profiles, except the MRRs, are $5 \mathrm{~km} \times 5 \mathrm{~km}$ means at each vertical level. For the Midpoint and Amanda Park sites, although the MRR units were located beyond this averaging area, they are located in the $20 \mathrm{~km} \times 20 \mathrm{~km}$ column box and have been included (asterisk in legends). Filled symbols show the $5 \mathrm{~km} \times 5 \mathrm{~km}$ mean surface values; open symbols indicate the means from ground instruments located within the column box but beyond the $5 \mathrm{~km} \times 5 \mathrm{~km}$ averaging area. "APU" indicates Parsivel disdrometers, and "Rayleigh" in the reflectivity panels indicates the reflectivity computed from the Parsivel observed DSD assuming Rayleigh scattering. Horizontal black line in each panel indicates the $0^{\circ} \mathrm{C}$ level. Because of the ranges of values, legends are not shown in the panels for the Grave's Creek precipitation rate and Upper East Fork reflectivity; note that these follow the same plotting convention as other panels.

making the system and the generated atmospheric column product more accessible to the precipitation research community. As changes are implemented, the SIMBA website (https://gpm-gv.gsfc.nasa.gov/SIMBA) will provide the most current version. Continuing updates to the system include adding support for L2B combined GMI and DPR precipitation estimates, L1C intercalibrated brightness temperatures, and L2 GPROF retrievals from GPM constellation partner sensors; additional ground-based scanning radars (e.g., NEXRAD not currently included in the GPM GV VN); refinements to the current modules (e.g., adjusting ground-based radar observations to a common reference frequency, incorporating a user-specified time interval of surface point observations, accounting for horizontal advection as radiosondes ascend, a more sophisticated spatial interpolation and/or weighting technique to obtain MRMS values for the column grid consistent with any user-specified horizontal spacing); and handling of measurements collected in situ and by remote sensing airborne platforms. Effort toward the latter may include a similar approach as that used by the open-source Airborne Weather Observations Toolkit (S. Nesbitt 2017, personal communication). In parallel to refinements to the SIMBA system itself, an ongoing effort at WPRF is developing a set of open-source (Python based) tools to promote usability of SIMBA's atmospheric column data product. 

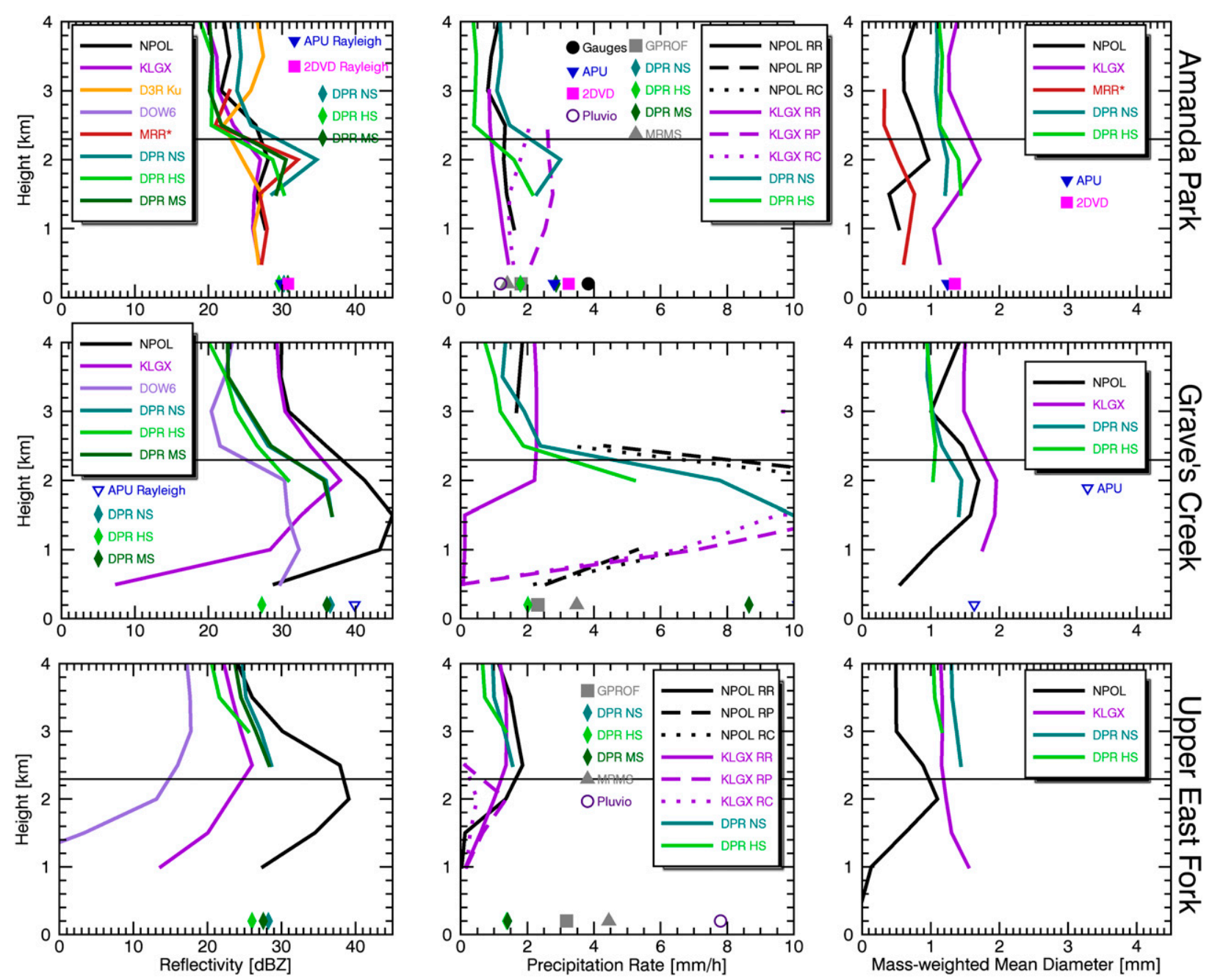

FIG. 8. (Continued)

SIMBA is flexible enough that users may also create their own modules for other platforms, provided the data structure format in the existing modules and column file writing procedure are followed (the framework includes documentation files, written as the system was developed, that detail each SIMBA component and module, as well as the data structures used in generating the new column file). Additionally, a new project in collaboration with the NASA Global Hydrology Resource Center Distributed Active Archive Center and the University of Alabama in Huntsville aimed at improving data exploration, access, and initial analysis capability for satellite-, aircraft-, and ground-based observations is poised to use SIMBA atmospheric column products as one of several input datasets (Conover et al. 2017). All of these ongoing efforts will allow SIMBA to evolve into a more robust tool over time, facilitating more efficient science.
Acknowledgments. We thank Bart Kelley for ensuring RSL in IDL compatibility with D3R and DOW radar data, Bob Morris for providing GPM VN's NASA PPS GPM satellite product reader utilities, and Pierre Kirstetter for providing MRMS products for GPM overpasses. We are grateful to the many individuals comprising the WPRF and GPM field campaign teams responsible for maintaining equipment and instrument installations. The GPM GV field campaign datasets, including OLYMPEX, are archived at the NASA Global Hydrology Resource Center Distributed Active Archive Center in Huntsville, Alabama (http://ghrc.nsstc.nasa.gov/ home/field-campaigns/gpmgv). Comments from three helpful reviewers improved the quality of this paper. This work was supported by an appointment to the NASA Postdoctoral Program at Marshall Space Flight Center, administered by Universities Space Research Association through a contract with NASA. The NASA GPM and 
Precipitation Measurement Missions Programs are also acknowledged for their support of this work.

\section{REFERENCES}

Adirosi, E., L. Baldini, N. Roberto, P. Gatlin, and A. Tokay, 2016: Improvement of vertical profiles of raindrop size distribution from micro rain radar using $2 \mathrm{D}$ video disdrometer measurements. Atmos. Res., 169, 404-415, https://doi.org/10.1016/ j.atmosres.2015.07.002.

Amitai, E., C. L. Unkrich, D. C. Goodrich, E. Habib, and B. Thill, 2012: Assessing satellite-based rainfall estimates in semiarid watersheds using the USDA-ARS Walnut Gulch gauge network and TRMM PR. J. Hydrometeor., 13, 1579-1588, https:// doi.org/10.1175/JHM-D-12-016.1.

Andrić, J., M. R. Kumjian, D. S. Zrnić, J. M. Straka, and V. M. Melnikov, 2013: Polarimetric signatures above the melting layer in winter storms: An observational and modeling study. J. Appl. Meteor. Climatol., 52, 682-700, https://doi.org/10.1175/JAMC-D-12-028.1.

Barnes, S. L., 1980: Report on a meeting to establish a common Doppler radar data exchange format. Bull. Amer. Meteor. Soc., 61, 1401-1404, https://doi.org/10.1175/1520-0477-61.11.1401.

Bringi, V.N., T. Tang, and V. Chandrasekar, 2004: Evaluation of a new polarimetrically based $Z-R$ relation. J. Atmos. Oceanic Technol., 21, 612-623, https://doi.org/10.1175/1520-0426(2004)021<0612: EOANPB $>2.0 . \mathrm{CO} ; 2$.

, L. Tolstoy, M. Thurai, and W. A. Petersen, 2015: Estimation of spatial correlation of drop size distribution parameters and rain rate using NASA's S-band polarimetric radar and 2D video disdrometer network: Two case studies from MC3E. J. Hydrometeor., 16, 1207-1221, https://doi.org/10.1175/JHM-D-14-0204.1.

Chandrasekar, V., A. Hou, E. Smith, V. N. Bringi, S. A. Rutledge, E. Gorgucci, W. A. Pertersen, and G. Skofronick-Jackson, 2008: Potential role of dual-polarization radar in the validation of satellite precipitation measurements: Rationale and opportunities. Bull. Amer. Meteor. Soc., 89, 1127-1145, https:// doi.org/10.1175/2008BAMS2177.1.

— NASA D3R during the GPM OLYMPEX field campaign. 2016 IEEE International Geoscience and Remote Sensing Symposium: Proceedings, IEEE, 2142-2145, https://doi.org/ 10.1109/IGARSS.2016.7729553.

Chen, H., and V. Chandrasekar, 2015: Characterization and estimation of light rainfall using NASA D3R observations during GPM IFloodS and IPHEx field campaigns. 2015 IEEE International Geoscience and Remote Sensing Symposium: Proceedings, IEEE, 2626-2629, https://doi.org/10.1109/ IGARSS.2015.7326351.

- — - and R. Bechini, 2017: An improved dual-polarization radar rainfall algorithm (DROPS2.0): Application in NASA IFloodS field campaign. J. Hydrometeor., 18, 917-937, https:// doi.org/10.1175/JHM-D-16-0124.1.

Chen, Y., H. Liu, J. An, U. Görsdorf, and F. H. Berger, 2015: A field experiment on the small-scale variability of rainfall based on a network of Micro Rain Radars and rain gauges. J. Appl. Meteor. Climatol., 54, 243-255, https://doi.org/10.1175/JAMC-D-13-0210.1.

Ciesielski, P., P. Haertel, R. Johnson, J. Wang, and S. Loehrer, 2012: Developing high-quality field program sounding datasets. Bull. Amer. Meteor. Soc., 93, 325-336, https://doi.org/ 10.1175/BAMS-D-11-00091.1.

Cifelli, R., W. Petersen, L. Carey, and S. Rutledge, 2002: Radar observations of the kinematic, microphysical, and precipitation characteristics of two MCSs in TRMM LBA. J. Geophys. Res., 170, 8077, https://doi.org/10.1029/2000JD000264.

Collis, S., A. Protat, and K.-S. Chung, 2010: The effect of radial velocity gridding artifacts on variationally retrieved vertical velocities. J. Atmos. Oceanic Technol., 27, 1239-1246, https:// doi.org/10.1175/2010JTECHA1402.1.

Conover, H., T. Berendes, P. N. Gatlin, M. Maskey, A. R. Naeger, and S. M. Wingo, 2017: Introducing the VISAGE projectVisualization for Integrated Satellite, Airborne, and Groundbased data Exploration. 2017 Fall Meeting, New Orleans, LA, Amer. Geophys. Union, Abstract IN41B-003.

Dolan, B., S. A. Rutledge, S. Lim, V. Chandrasekar, and M. Thurai, 2013: A robust C-band hydrometeor identification algorithm and application to a long-term polarimetric radar dataset. J. Appl. Meteor. Climatol., 52, 2162-2186, https://doi.org/ 10.1175/JAMC-D-12-0275.1.

Gatlin, P. N., W. A. Petersen, and S. M. Wingo, and D. B. Wolff, 2017: Radar and disdrometer observations of topographical effects on the melting layer and resultant RSD. 38th Conf. on Radar Meteorology, Chicago, IL, Amer. Meteor. Soc., 5A.6, https://ams. confex.com/ams/38RADAR/meetingapp.cgi/Paper/320601.

Germann, U., G. Galli, M. Boscacci, and M. Bolliger, 2006: Radar precipitation measurement in a mountainous region. Quart. J. Roy. Meteor. Soc., 132, 1669-1692, https://doi.org/10.1256/ qj.05.190.

GSFC, 2017a: NASA Global Precipitation Measurement (GPM) Level $1 \mathrm{C}$ algorithms. Version 1.8, NASA Goddard Space Flight Center Algorithm Theoretical Basis Doc., 72 pp., https://pps.gsfc.nasa.gov/ Documents/L1C_ATBD_v1.8_V08.pdf.

_ 2017b: Global Precipitation Measurement (GPM) Mission Algorithm Theoretical Basis Document GPROF2017 Version 1 and Version 2 (used in GPM V5 processing). 64 pp., http://rain. atmos.colostate.edu/ATBD/ATBD_GPM_October1_2017.pdf.

Gourley, J. J., Y. Hong, Z. L. Flamig, L. Li, and J. Wang, 2010: Intercomparison of rainfall estimates from radar, satellite, gauge, and combinations for a season of record rainfall. J. Appl. Meteor. Climatol., 49, 437-452, https://doi.org/10.1175/ 2009JAMC2302.1.

Grecu, M., W. S. Olson, S. J. Munchak, S. Ringerud, L. Liao, Z. S. Haddad, B. L. Kelley, and S. F. McLaughlin, 2016: The GPM combined algorithm. J. Atmos. Oceanic Technol., 33, 22252245, https://doi.org/10.1175/JTECH-D-16-0019.1.

Harikumar, R., S. Sampath, and V. Sasi Kumar, 2012: Altitudinal and temporal evolution of raindrop size distribution observed over a tropical station using a K-band radar. Int. J. Remote Sens., 33, 3286-3300, https://doi.org/10.1080/01431161.2010.549853.

Heistermann, M., and Coauthors, 2015: The emergence of opensource software for the weather radar community. Bull. Amer. Meteor. Soc., 96, 117-128, https://doi.org/10.1175/BAMS-D13-00240.1.

Hirpa, F., M. Gebremichael, and T. Hopson, 2010: Evaluation of high-resolution satellite precipitation products over very complex terrain in Ethiopia. J. Appl. Meteor. Climatol., 49, 1044-1051, https://doi.org/10.1175/2009JAMC2298.1.

Hou, A. Y., and Coauthors, 2014: The Global Precipitation Measurement (GPM) mission. Bull. Amer. Meteor. Soc., 95, 701722, https://doi.org/10.1175/BAMS-D-13-00164.1.

Houze, R. A., Jr., and Coauthors, 2017: The Olympic Mountains Experiment (OLYMPEX). Bull. Amer. Meteor. Soc., 98, 2167-2188, https://doi.org/10.1175/BAMS-D-16-0182.1.

Iguchi, T., S. Seto, R. Meneghini, N. Yoshida, J. Awaka, M. Le, V. Chandrasekar, and T. Kubota, 2017: GPM/DPR level-2 algorithm theoretical basis document. NASA Goddard Space 
Flight Center, 81 pp., https://pps.gsfc.nasa.gov/Documents/ ATBD_DPR_201708_whole_1.pdf.

Jensen, M., and Coauthors, 2016: The Midlatitude Continental Convective Clouds Experiment (MC3E). Bull. Amer. Meteor. Soc. 97, 1667-1686, https://doi.org/10.1175/BAMS-D-14-00228.1.

Kennedy, P., and S. Rutledge, 2011: S-band dual-polarization radar observations of winter storms. J. Appl. Meteor. Climatol., 50 , 844-858, https://doi.org/10.1175/2010JAMC2558.1.

Kim, J., M. Ou, J. Park, K. Morris, M. Schwaller, and D. Wolff, 2014: Global Precipitation Measurement (GPM) ground validation $(\mathrm{GV})$ prototype in the Korean Peninsula. J. Atmos. Oceanic Technol., 31, 1902-1921, https://doi.org/10.1175/ JTECH-D-13-00193.1.

Kingsmill, D. E., P. J. Neiman, F. M. Ralph, and A. B. White, 2006: Synoptic and topographic variability of northern California precipitation characteristics in landfalling winter storms observed during CALJET. Mon. Wea. Rev., 134, 2072-2094, https://doi.org/ 10.1175/MWR3166.1.

Kirstetter, P., and Coauthors, 2012: Toward a framework for systematic error modeling of spaceborne precipitation radar with NOAA/ NSSL ground radar-based National Mosaic QPE. J. Hydrometeor., 13, 1285-1300, https://doi.org/10.1175/JHM-D-11-0139.1.

Kulie, M. S., R. Bennartz, T. J. Greenwald, Y. Chen, and F. Weng, 2010: Uncertainties in microwave properties of frozen precipitation: Implications for remote sensing and data assimilation. J. Atmos. Sci., 67, 3471-3487, https://doi.org/10.1175/ 2010JAS3520.1.

Kumjian, M. R., S. A. Rutledge, R. M. Rasmussen, P. C. Kennedy, and M. Dixon, 2014a: High-resolution polarimetric radar observations of snow-generating cells. J. Appl. Meteor. Climatol., 53, 1636-1658, https://doi.org/10.1175/JAMC-D-13-0312.1.

_ A. P. Khain, N. Benmoshe, E. Ilotoviz, A. V. Ryzhkov, and V. T. J. Phillips, 2014b: The anatomy and physics of $Z_{\mathrm{DR}}$ columns: Investigating a polarimetric radar signature with a spectral bin microphysical model. J. Appl. Meteor. Climatol., 53, 1820-1843, https://doi.org/10.1175/JAMC-D-13-0354.1.

Kummerow, C. D., D. L. Randel, M. Kulie, N. Wang, R. Ferraro, S. J. Munchak, and V. Petkovic, 2015: The evolution of the Goddard profiling algorithm to a fully parametric scheme. J. Atmos. Oceanic Technol., 32, 2265-2280, https://doi.org/ 10.1175/JTECH-D-15-0039.1.

Marks, D., D. Wolff, L. Carey, and A. Tokay, 2011: Quality control and calibration of the dual-polarization radar at Kwajalein, RMI. J. Atmos. Oceanic Technol., 28, 181-196, https://doi.org/ 10.1175/2010JTECHA1462.1.

Medina, S., and R. A. Houze Jr., 2015: Small-scale precipitation elements in midlatitude cyclones crossing the California Sierra Nevada. Mon. Wea. Rev., 143, 2842-2870, https://doi.org/ 10.1175/MWR-D-14-00124.1.

_ B. Smull, R. A. Houze Jr., and M. Steiner, 2005: Cross-barrier flow during orographic precipitation events: Results from MAP and IMPROVE. J. Atmos. Sci., 62, 3580-3598, https:// doi.org/10.1175/JAS3554.1.

_ E. Sukovich, and R. A. Houze Jr., 2007: Vertical structures of precipitation in cyclones crossing the Oregon Cascades. Mon. Wea. Rev., 135, 3565-3586, https://doi.org/10.1175/MWR3470.1.

Mei, Y., E. N. Anagnostou, E. I. Nikolopoulos, and M. Borga, 2014: Error analysis of satellite precipitation products in mountainous basins. J. Hydrometeor., 15, 1778-1793, https://doi.org/ 10.1175/JHM-D-13-0194.1.

Minder, J. R., T. W. Letcher, L. S. Campbell, P. G. Veals, and J. Steenburgh, 2015: The evolution of lake-effect convection during landfall and orographic uplift as observed by profiling radars. Mon. Wea. Rev., 143, 4422-4442, https://doi.org/ 10.1175/MWR-D-15-0117.1.

Mohr, C. G., L. J. Miller, R. L. Vaughn, and H. W. Frank, 1986: The merger of mesoscale datasets into a common Cartesian format for efficient and systematic analyses. J. Atmos. Oceanic Technol., 3, 143-161, https://doi.org/10.1175/1520-0426(1986) $003<0143$ :TMOMDI $>2.0$.CO;2.

Olson, W., H. Masunaga, and the GPM Combined Radar-Radiometer Algorithm Team, 2016: GPM combined radar-radiometer precipitation. Version 4, NASA Goddard Space Flight Center Algorithm Theoretical Basis Doc., 63 pp., https://pps.gsfc.nasa.gov/ Documents/Combined_algorithm_ATBD.V04.rev.pdf.

Oye, R., C. Mueller, and S. Smith, 1995: Software for radar translation, visualizations, editing, and interpolation. Preprints, 27th Conf. on Radar Meteorology, Vail, CO, Amer. Meteor. Soc., 359-361.

Pabla, C. S., S. M. Wingo, D. A. Marks, W. A. Petersen, and P. N. Gatlin, 2017: Comparing GPM satellite to ground platform measurements: Case studies from the NASA Wallops Precipitation Science Research Facility. 38th Conf. on Radar Meteorology, Chicago, IL, Amer. Meteor. Soc., 111, https://ams.confex.com/ams/ 38RADAR/meetingapp.cgi/Paper/320403.

Peters, G., B. Fischer, H. Münster, M. Clemens, and A. Wagner, 2005: Profiles of raindrop size distributions as retrieved by microrain radars. J. Appl. Meteor., 44, 1930-1949, https://doi.org/ 10.1175/JAM2316.1.

Petersen, W. A., L. McMurdie, R. A. Houze, J. Zagrodnik, S. Tanelli, J. Lundquist, and J. Wurman, 2016: The Olympic Mountains Experiment. Meteorological Technology International, September 2016, UKIP Media and Events, Dorking, United Kingdom, 22-26, http://www.ukimediaevents.com/publication/ 997185af/24

, A. Tokay, K. R. Morris, L. P. D'Adderio, D. B. Wolff, and P. N. Gatlin, 2017: Polarimetric radar verification of GPM satellitebased retrieval of the raindrop size distribution. 38th Conf. on Radar Meteorology, Chicago, IL, Amer. Meteor. Soc., 7B.4, https:// ams.confex.com/ams/38RADAR/meetingapp.cgi/Paper/320335.

- , R. Houze, and L. McMurdie, 2018: GPM Ground Validation Olympic Mountain Experiment (OLYMPEX) field campaign data collection. NASA EOSDIS Global Hydrology Resource Center DAAC, accessed March 2017, https:/doi.org/10.5067/ GPMGV/OLYMPEX/DATA101.

Pippitt, J., D. Marks, and D. Wolff, 2013: Dual polarimetric quality control for NASA's Global Precipitation Measurement (GPM) mission Ground Validation program. 36th Conf. on Radar Meteorology, Breckenridge, CO, Amer. Meteor. Soc., 253, https:// ams.confex.com/ams/36Radar/webprogram/Paper228522.html.

_ D. B. Wolff, W. A. Petersen, and D. A. Marks, 2015: Data and operational processing for NASA's GPM Ground Validation program. 37th Conf. on Radar Meteorology, Norman, OK, Amer. Meteor. Soc., 111, https://ams.confex.com/ams/37RADAR/ webprogram/Paper275627.html.

Schwaller, M. R., and K. R. Morris, 2011: A ground validation network for the Global Precipitation Measurement mission. J. Atmos. Oceanic Technol., 28, 301-319, https://doi.org/10.1175/2010JTECHA1403.1.

Skofronick-Jackson, G., and Coauthors, 2015: Global Precipitation Measurement Cold Season Precipitation Experiment (GCPEx): For measurement's sake, let it snow. Bull. Amer. Meteor. Soc., 96, 1719-1741, https://doi.org/10.1175/BAMS-D-13-00262.1.

— (GPM) mission for science and society. Bull. Amer. Meteor. Soc., 98, 1679-1695, https://doi.org/10.1175/BAMS-D-15-00306.1.

Tan, J., W. A. Petersen, and A. Tokay, 2016: A novel approach to identify sources of errors in IMERG for GPM ground 
validation. J. Hydrometeor., 17, 2477-2491, https://doi.org/ 10.1175/JHM-D-16-0079.1.

Testud, J., and M. Chong, 1983: Three-dimensional wind field analysis from dual-Doppler radar data. Part I: Filtering, interpolating, and differentiating the raw data. J. Climate Appl. Meteor., 22, 1204-1215, https://doi.org/10.1175/1520-0450(1983)022<1204: TDWFAF $>2.0 . \mathrm{CO} ; 2$.

, S. Oury, R. A. Black, P. Amayenc, and X. Dou, 2001: The concept of "normalized" distribution to describe raindrop spectra: A tool for cloud physics and cloud remote sensing. J. Appl. Meteor., 40, 1118-1140, https://doi.org/10.1175/1520-0450(2001)040<1118: TCONDT>2.0.CO;2.

Thurai, M., P. Gatlin, V. N. Bringi, W. Petersen, P. Kennedy, B. Notaroš, and L. Carey, 2017: Toward completing the raindrops size spectrum: Case studies involving 2D-video disdrometer, droplet spectrometer, and polarimetric radar measurements. J. Appl. Meteor. Climatol., 56, 877-896, https://doi.org/10.1175/JAMC-D-16-0304.1.

Tokay, A., A. Kruger, and W. F. Krajewski, 2001: Comparison of drop size distribution measurements by impact and optical disdrometers. J. Appl. Meteor., 40, 2083-2097, https://doi.org/ 10.1175/1520-0450(2001)040<2083:CODSDM>2.0.CO;2.

, P. Hartmann, A. Battaglia, K. S. Gage, W. L. Clark, and C. R. Williams, 2009: A field study of reflectivity and $Z-R$ relations using vertically pointing radars and disdrometers. J. Atmos. Oceanic Technol., 26, 1120-1134, https://doi.org/ 10.1175/2008JTECHA1163.1.

, W. A. Petersen, P. Gatlin, and M. Wingo, 2013: Comparison of raindrop size distribution measurements by collocated disdrometers. J. Atmos. Oceanic Technol., 30, 1672-1690, https://doi.org/10.1175/JTECH-D-12-00163.1.

Tromel, S., M. R. Kumjian, A. V. Ryzhkov, C. Simmer, and M. Diederich, 2013: Backscatter differential phase-Estimation and variability. J. Appl. Meteor. Climatol., 52, 2529-2548, https:// doi.org/10.1175/JAMC-D-13-0124.1.

Unidata, 2016: NetCDF data format. UCAR/Unidata Program Center, https://doi.org/10.5065/D6H70CW6.
Vega, M., V. Chandrasekar, J. Carswell, R. Beauchamp, M. Schwaller, and C. Nguyen, 2014: Salient features of the dual-frequency, dual-polarized, Doppler radar for remote sensing of precipitation. Radio Sci., 49, 1087-1105, https:// doi.org/10.1002/2014RS005529.

Vulpiani, G., M. Montopoli, L. D. Passeri, A. G. Gioia, P. Giordano, and F. S. Marzano, 2012: On the use of dual-polarized C-band radar for operational rainfall retrieval in mountainous areas. J. Appl. Meteor. Climatol., 51, 405-425, https://doi.org/10.1175/ JAMC-D-10-05024.1.

Wang, J., B. Fisher, and D. Wolff, 2008: Estimating rain rates from tipping-bucket rain gauge measurements. J. Atmos. Oceanic Technol., 25, 43-56, https://doi.org/10.1175/ 2007JTECHA895.1.

Wolff, D. B., and B. L. Kelley, 2009: NASA's Radar Software Library (RSL) and RSL in IDL. 34th Conf. on Radar Meteorology, Williamsburg, VA, Amer. Meteor. Soc., P10.5, https://ams.confex.com/ams/34Radar/techprogram/ paper_155299.htm.

_ , and Coauthors, 2015: GPM radar studies at NASA's Wallops Precipitation Research Facility. 37th Conf. on Radar Meteorology, Norman, OK, Amer. Meteor. Soc., 163, https://ams. confex.com/ams/37RADAR/webprogram/Paper276039.html.

Wurman, J., J. Straka, E. Rasmussen, M. Randall, and A. Zahrai, 1997: Design and deployment of a portable, pencil-beam, pulsed, 3-cm Doppler radar. J. Atmos. Oceanic Technol., 14, 1502-1512, https://doi.org/10.1175/1520-0426(1997)014<1502: DADOAP $>2.0 . \mathrm{CO} ; 2$.

Zagrodnik, J. P., L. A. McMurdie, and R. A. Houze Jr., 2018: Stratiform precipitation processes in cyclones passing over a coastal mountain range. J. Atmos. Sci., 75, 983-1004, https:// doi.org/10.1175/JAS-D-17-0168.1.

Zhang, G., and Coauthors, 2016: Multi-Radar Multi-Sensor quantitative precipitation estimation: Initial operating capabilities. Bull. Amer. Meteor. Soc., 97, 621-637, https://doi.org/ 10.1175/BAMS-D-14-00174.1. 